\title{
Trimeprazine increases IRS2 in human islets and promotes pancreatic $\beta$ cell growth and function in mice
}

\author{
Alexandra Kuznetsova, ${ }^{1}$ Yue Yu, ${ }^{1}$ Jennifer Hollister-Lock, ${ }^{2}$ Lynn Opare-Addo, ${ }^{1}$ Aldo Rozzo, ${ }^{1}$ \\ Marianna Sadagurski, ${ }^{1}$ Lisa Norquay, ${ }^{1}$ Jessica E. Reed, ${ }^{3}$ Iham El Khattabi, ${ }^{2}$ Susan Bonner-Weir, ${ }^{2}$ \\ Gordon C. Weir, ${ }^{2}$ Arun Sharma, ${ }^{2}$ and Morris F. White ${ }^{1}$ \\ 'Division of Endocrinology, Department of Medicine, Boston Children's Hospital, Harvard Medical School, Boston, \\ Massachusetts, USA. '2Section of Islet Cell and Regenerative Biology, Department of Medicine, Joslin Diabetes Center, \\ Harvard Medical School, Boston, Massachusetts, USA. ${ }^{3}$ Housey Pharmaceutical Research Laboratories, \\ Southfield, Michigan, USA.
}

The capacity of pancreatic $\beta$ cells to maintain glucose homeostasis during chronic physiologic and immunologic stress is important for cellular and metabolic homeostasis. Insulin receptor substrate 2 (IRS2) is a regulated adapter protein that links the insulin and IGF1 receptors to downstream signaling cascades. Since strategies to maintain or increase IRS2 expression can promote $\beta$ cell growth, function, and survival, we conducted a screen to find small molecules that can increase IRS2 mRNA in isolated human pancreatic islets. We identified 77 compounds, including 15 that contained a tricyclic core. To establish the efficacy of our approach, one of the tricyclic compounds, trimeprazine tartrate, was investigated in isolated human islets and in mouse models. Trimeprazine is a first-generation antihistamine that acts as a partial agonist against the histamine H1 receptor (H1R) and other GPCRs, some of which are expressed on human islets. Trimeprazine promoted CREB phosphorylation and increased the concentration of IRS2 in islets. IRS2 was required for trimeprazine to increase nuclear $\mathrm{Pdx} 1$, islet mass, $\beta$ cell replication and function, and glucose tolerance in mice. Moreover, trimeprazine synergized with anti-CD3 Abs to reduce the progression of diabetes in NOD mice. Finally, it increased the function of human islet transplants in streptozotocin-induced (STZ-induced) diabetic mice. Thus, trimeprazine, its analogs, or possibly other compounds that increase IRS2 in islets and $\beta$ cells without adverse systemic effects might provide mechanism-based strategies to prevent the progression of diabetes.

Conflict of interest: The authors have declared that no conflict of interest exists.

Submitted: January 8, 2015 Accepted: February 16, 2016 Published: March 17, 2016

Reference information: JCI Insight. 2016;1(3):e80749. doi:10.1172/ji.insight.80749.

\section{Introduction}

The incidence of diabetes has reached about 366 million cases worldwide (1). At least $90 \%$ of all cases are type 2 diabetes mellitus (T2DM), and the incidence of type 1 diabetes (T1DM) is increasing by about $4 \%$ per year. T1DM is an autoimmune disorder with incomplete penetrance that leads to progressive islet damage and catastrophic insulin deficiency when most of the $\beta$ cells are destroyed and fail to regenerate (2). A specific HLA haplotype accounts for more than 50\% of the genetic risk for T1DM, but many other genetic loci, including insulin itself, can contribute to the autoimmune component (3). Although autoimmunity needs to be managed in T1DM patients, compounds that promote $\beta$ cell growth, function, or survival might counterbalance the immunologic stress to slow the progression and maintain sufficient $\beta$ cell mass in T1DM

T2DM is a heterogeneous metabolic disease. Hundreds of genes are implicated in the regulation of nutrient homeostasis, including the components of the insulin-signaling cascade. During the past decade, genome-wide association studies revealed more than 60 genetic loci with modest or weak, but significant, effects on the risk for T2DM (4). Many, but not all, of these loci are located near genes with functional impact on insulin secretion, insulin resistance, or glucose tolerance. Whether the current set of genes will converge on a short list of pathways and signaling networks that modulate insulin secretion and action during stress remains to be established (4).

Deletion of the insulin receptor substrate 2 (IRS2) gene in mice causes diabetes as a result of peripheral and central insulin resistance, which is exacerbated by $\beta$ cell failure (5). Restoring Irs 2 in the $\beta$ cells 
alone can maintain or promote the expansion of $\beta$ cell mass in Irs2-deficient (Irs2 ${ }^{-/}$) mice, which promotes glucose tolerance by sustained compensatory hyperinsulinemia (6). Islets expressing transgenic Irs 2 can prevent diabetes more effectively than can WT islets upon transplantation into insulin-resistant or diabetic mice (7). Moreover, NOD mice with transgenic Irs2 in $\beta$ cells are more resistant to diabetes during anti-CD3 Ab therapy (8). Since IRS2 is a highly regulated "node" in insulin target tissues and $\beta$ cells, compounds that upregulate Irs 2 might promote $\beta$ cell function during chronic immunologic or physiologic stress encountered during the progression of diabetes (9).

Several studies show that IRS2 expression is controlled in $\beta$ cells by the cyclic AMP-regulated (cAMP-regulated) and $\mathrm{Ca}^{2+}$-regulated transcription factors. Glucose itself is an important regulator of intracellular $\mathrm{Ca}^{2+}$ that triggers immediate insulin secretion, but also upregulates IRS2 expression in $\beta$ cells (10). $\beta$ cells also express many GPCRs, which regulate $\beta$ cell function through the activation of heterotrimeric $\mathrm{G}$ proteins, including $\mathrm{G} \alpha_{\mathrm{s}} \rightarrow \mathrm{cAMP}$ (promotes) or $\mathrm{G}_{\mathrm{i}}$ - tcAMP (inhibits), each of which regulates PKA and EPAC signaling; or $\mathrm{G} \alpha_{\mathrm{q}} \rightarrow$ phospholipase $\mathrm{C} \beta$ (PLC $\beta$ ), which mediates the production of diacylglycerol (DAG $\rightarrow$ PKC signaling) and inositol 1,4,5-trisphosphate (IP3 $\rightarrow \mathrm{Ca}^{2+}$ signaling) (11). In addition, cAMP- and $\mathrm{Ca}^{2+}$-activated transcription factors are linked to the induction of IRS2 gene expression in $\beta$ cells through PKA $\rightarrow$ CRTC2/CREB or $\mathrm{Ca}^{2+} \rightarrow$ calcineurin $\rightarrow$ NFAT (12-14). Thus, compounds that activate GPCRs in $\beta$ cells and increase IRS2 expression without adverse effects might provide mechanism-based treatments for diabetes.

Recent efforts to identify new drugs to restore normal insulin secretion have focused on well-established or newly characterized GPCRs, including acetylcholine $\rightarrow \mathrm{mAChRs} \rightarrow \mathrm{G}_{\mathrm{q}} / \mathrm{G}_{11} ; \mathrm{GLP} 1 \mathrm{R} \rightarrow \mathrm{G}_{\alpha} ; \mathrm{GRP} 40 \rightarrow \mathrm{G}_{\mathrm{q}}$; $\mathrm{GPR} 119 \rightarrow \mathrm{G}_{\mathrm{s}}$; GPR120 $\rightarrow \mathrm{G}_{\mathrm{q}}$; and others $(11,15)$. A drug that engages multiple targets might also have beneficial effects if the signals converge on a common signaling cascade (16). Whereas the immediate effect of cAMP or $\mathrm{Ca}^{2+}$ usually increases insulin secretion, persistent effects include improved $\beta$ cell function and growth that might be related, at least in part, to increased IRS2 expression $(17,18)$. We set out to identify small molecules - regardless of the mechanism - that increase the expression and synthesis of IRS2 in human pancreatic islets in vitro and then determine whether they can promote $\beta$ cell growth and glucose homeostasis in mice. We identified 77 compounds and investigated trimeprazine, a tricyclic compound with an established safety profile in children and animals (19).

\section{Results}

Identification of compounds that increase IRS2 mRNA levels in human islets. We developed a compound screen based on the Panomics QuantiGene 2.0 assay system to identify small molecules that increase IRS2 mRNA concentrations in isolated human pancreatic islets (Figure 1A). Islets (70-100 islets) were distributed onto 96-well plates and incubated for 4 hours with $1 \%$ (v/v) DMSO alone or with $\mathrm{Bt}_{2} \mathrm{cAMP}$, exendin-4, or compounds from 4 commercially available chemical libraries: Biomol ICCB Known Bioactives 1 and 2; Ninds Custom Collection 2; and Prestwick 1 Collection (see Methods for details). After subtraction of the average plate baseline (DMSO alone), the IRS2 mRNA concentration in each well was normalized to the plate median, and the complete set of normalized results were combined and analyzed by a generalized linear model (GLM) to identify compounds that increased IRS2 mRNA above the 95th percentile ( $>2.4$-fold, $P<$ 0.05 ) relative to the DMSO baseline (Figure 1B). $\mathrm{Bt}_{2} \mathrm{cAMP}$ and 77 of 3,300 other tested compounds $(2.3 \%)$ met this arbitrary cutoff (Supplemental Table 1; supplemental material available online with this article; doi:10.1172/jci.insight.80749DS1). By contrast, many compounds reduced the expression of IRS2 below the 5th percentile ( $<-1.8$-fold, $P<0.05$ ), but these were not investigated (Figure 1B). Unexpectedly, exendin-4 did not stimulate IRS2 mRNA in human islets, whereas $\mathrm{Bt}_{2} \mathrm{cAMP}$ always increased IRS2 mRNA by approximately 5 -fold (data not shown).

IRS2 gene expression in $\beta$ cells can be regulated by several transcription factor cascades including $\mathrm{cAMP} \rightarrow \mathrm{CREB} \rightarrow \mathrm{IRS} 2 ; \mathrm{Ca}^{2+} \rightarrow$ calcineurin $\rightarrow \mathrm{NFAT} \rightarrow \mathrm{IRS} 2$ and $\mathrm{PI} 3 \mathrm{~K} \rightarrow \mathrm{AKT} 1 \mathrm{FOXO} 1 \rightarrow \mathrm{IRS} 2(12-14,20)$. Regardless, the mechanism of IRS2 upregulation is unknown for most of the identified compounds, and a systematic mechanistic investigation of each compound was beyond the scope of this work; however, several of the identified compounds are consistent with known transcriptional control mechanisms. For example, forskolin, IBMX, trequinsin, YC-1 and zardaverine are expected to increase cAMP concentration to promote $\mathrm{CREB} \rightarrow \mathrm{IRS} 2$ signaling (18). Other compounds are thought to increase $\mathrm{Ca}^{2+}$ concentrations by directly increasing $\mathrm{Ca}^{2+}$ influx (A-23187, benzamil, U-50488), inhibiting $\mathrm{K}^{+}$efflux (repaglinide), or inhibiting $\mathrm{Na}^{+}-\mathrm{Ca}^{2+}$ exchange (ouabain, digoxin, digoxigenin, strophanthidin). Moreover, several kinase inhibitors 
A
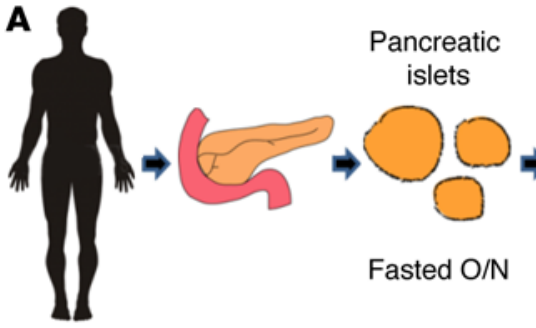

Fasted O/N

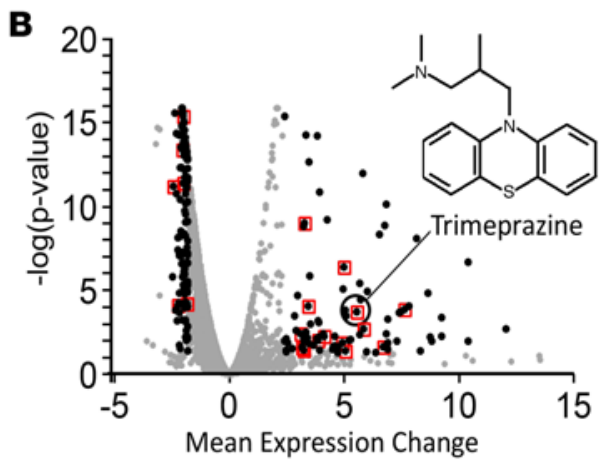

C

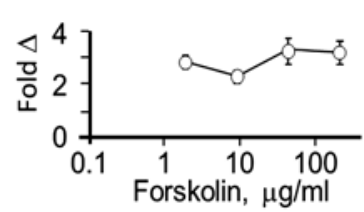<smiles>C=CC1(C)CC(=O)C2C(O1)C(OC(C)=O)C(O)C(C)C1C(C)CCC(=O)C21</smiles>

D

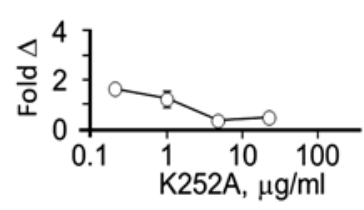

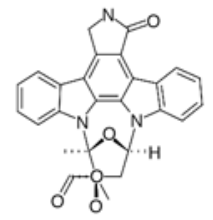

E

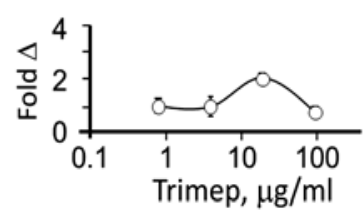<smiles>CC(C)CC(C)Cn1c2ccccc2c2ccccc21</smiles>

F

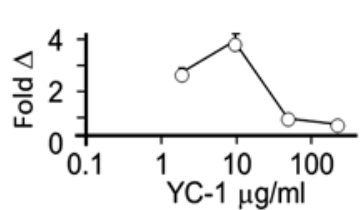<smiles>COc1ccc(-c2nn(Cc3ccccc3)c3ccccc23)o1</smiles>

G

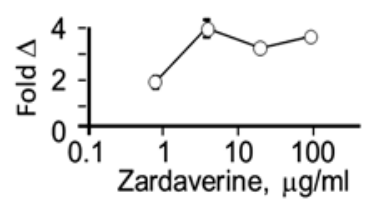<smiles>COc1cc(-c2ccc(=O)[nH]n2)ccc1OC(F)F</smiles>

Compound $(\mathrm{mg} / \mathrm{kg})$
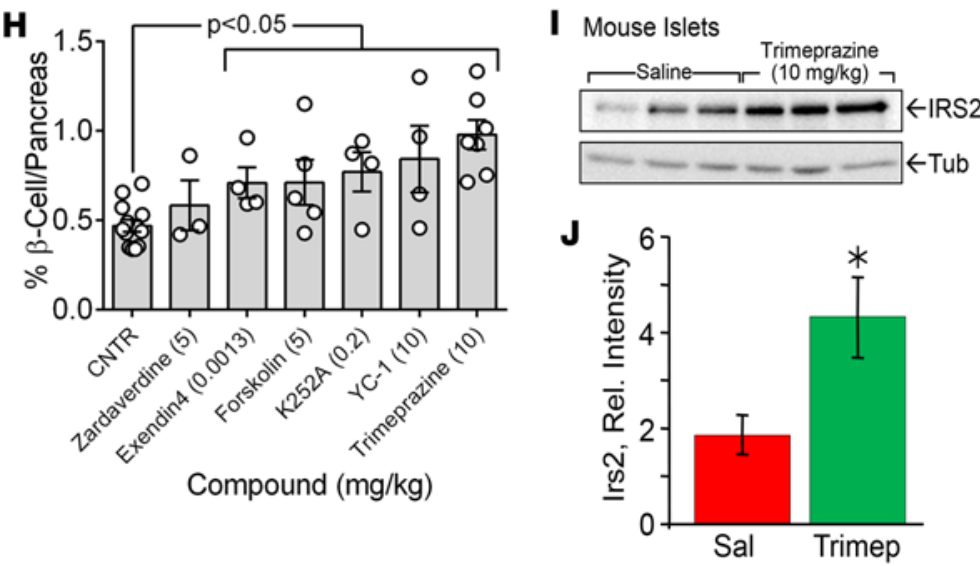

(a)

Figure 1. Compounds that increase IRS2 expression in human islets. (A) The screening strategy. (B) Volcano plot of mRNA IRS2 expression in islets treated for 4 hours with each compound. The -log ( $P$ value) and mean expression change were calculated by generalized linear regression for 2 independent single measurements for each test compound against DMSO control expression. A mean expression change of more than the 95 th percentile or less than the 5 th percentile $(P<0.05)$ are indicated with black circles. Tricyclic compounds are highlighted by a red box, and trimeprazine is highlighted. (C-G) Effect of forskolin, trimeprazine, zardanerine, K252A, and YC-1 on IRS2 mRNA expression in human islets from 3 different donors compared with the DMSO control analyzed at 4 different concentrations ( $n=12$; fold $\Delta \pm 95 \% \mathrm{Cl}$ ). (H) C57BL/6) male mice were treated with saline or the indicated compound by i.p. injection once a day for 3 weeks starting at 6 weeks of age. Exendin- 4 was used as a positive control. Insulin-positive areas and total pancreas section areas were assessed by Spot Advanced Software (http://www.spotimaging.com/software/). Graph shows the daily dose of compound that caused the greatest increase in $\beta$ cell area. Two whole pancreas sections were analyzed for each mouse, and each bar represents the average $\beta$ cell area for at least 4 mice. A GLM was used to determine the mean \pm SEM and to obtain the Bonferroni-corrected $P$ value, with treatment as the factor. (I and $\mathbf{J}$ ) C57BL/6] male mice were injected i.p. with trimeprazine tartrate once a day for 7 days starting at 6 weeks of age. The islets were isolated and analyzed by immunoblotting. Irs2 intensity was normalized against tubulin intensity, and the average normalized Irs $\pm 95 \% \mathrm{CI}$ was determined. ${ }^{*} P=0.27$, by $\mathrm{GLM}$ and Bonferroni correction, with treatment as the factor. Cntr, control; GLM, generalized linear model; IRS2, insulin receptor substrate 2; 0/N, overnight; Rel., relative; Sal, saline; Tub, tubulin; Trimep, trimeprazine.

that might inhibit AKT and activate FOXO were identified including A3, K252a, LY294002, ML9, PP1, and wortmannin.

Tricyclic compounds with known physiologic effects but poorly defined or multiple signaling mechanisms composed a major subset of the identified compounds (Figure 2). Among the tricyclic compounds, 15 compounds significantly increased IRS2 expression above the 95th percentile, and 5 significantly reduced IRS2 expression below the 5th percentile (Figure 2). These compounds contained a common tricyclic pharmacophore with either 6,6,6 rings or 6,7,6 rings and a 2-3 atom side chain attached to a substi- 


\begin{tabular}{|c|c|c|c|c|c|c|c|c|}
\hline Structure & name & conc & $\Delta$ & SE & p & $\begin{array}{l}\mathrm{H} 1 \mathrm{R} \\
(\mathrm{nM})\end{array}$ & $\begin{array}{c}\alpha 1 \mathrm{a} \\
(\mathrm{nM})\end{array}$ & action \\
\hline & Maprotiline & $\begin{array}{r}2 \mathrm{mg} / \mathrm{ml} \\
10 \mathrm{mg} / \mathrm{ml}\end{array}$ & $\begin{array}{l}7.5 \\
5.0\end{array}$ & $\begin{array}{l}0.2 \\
1.0\end{array}$ & $\begin{array}{l}0.0001 \\
0.0001\end{array}$ & 2.0 & 0.2 & $\begin{array}{l}\text { antidepressant; strong norepinephrine } \\
\text { reuptake inhibitor with only weak effects } \\
\text { on serotonin and dopamine reuptake }\end{array}$ \\
\hline & Protriptyline & $2 \mathrm{mg} / \mathrm{ml}$ & 6.9 & 4.1 & 0.0400 & 63 & & \\
\hline & Nortriptyline & $\begin{array}{r}2 \mathrm{mg} / \mathrm{ml} \\
10 \mathrm{mg} / \mathrm{ml}\end{array}$ & $\begin{array}{l}6.7 \\
3.9\end{array}$ & $\begin{array}{l}2.9 \\
1.5\end{array}$ & $\begin{array}{l}0.0225 \\
0.0100\end{array}$ & 0.1 & 39.8 & $\begin{array}{l}\text { Active metabolite of amitriptyline. Inhibits } \\
\text { reuptake of norepinephrine }>\text { serotonin }> \\
\text { dopamine. Antagonizes H1R }>5-\mathrm{HT} 2> \\
\text { a1-adrenergic, mACh }>5-\mathrm{HT} 1\end{array}$ \\
\hline & Cyproheptadine & $2 \mathrm{mg} / \mathrm{ml}$ & 6.5 & 1.1 & $4.2 \times 10^{-9}$ & 0.1 & 39.8 & $\begin{array}{l}\text { antihistamine; antagonist of } H 1 R>5- \\
H T 2 A R \approx 5-H T 2 B R \approx 5-H T 2 C R>m A C h R \approx \\
D 3 R\end{array}$ \\
\hline & Trimeprazine & $2 \mathrm{mg} / \mathrm{ml}$ & 5.8 & 1.9 & 0.0020 & 1.3 & 6.0 & $\begin{array}{l}\text { H1R antagonist; antipruritic, sedative, } \\
\text { hypnotic, antiemetic; not used as an } \\
\text { antipsychotic }\end{array}$ \\
\hline & Ethopropazine & $2 \mathrm{mg} / \mathrm{ml}$ & 5.6 & 1.5 & 0.0002 & & & $\begin{array}{l}\text { an antiparkinsonian agent that has } \\
\text { anticholinergic, antihistamine, and } \\
\text { antiadrenergic actions; }\end{array}$ \\
\hline & Amoxapine & $2 \mathrm{mg} / \mathrm{ml}$ & 5.1 & 0.6 & 0.0003 & & & $\begin{array}{l}\text { reuptake inhibitor of serotonin and } \\
\text { norepinephrine, respectively, and binds to } \\
5-\mathrm{HT} 2,3,6 \text { and } 5-\mathrm{HT} 7, \mathrm{D} 2, \mathrm{a} 1 \text {-adrenergic, } \\
\text { D3, D4 and H1 receptors }\end{array}$ \\
\hline & Imipramine & $2 \mathrm{mg} / \mathrm{ml}$ & 5.1 & 2.5 & 0.0400 & 25 & 31.6 & $\begin{array}{l}\text { serotonin and noradrenalin transporter } \\
\text { inhibitor; }\end{array}$ \\
\hline & Dosulepin & $2 \mathrm{mg} / \mathrm{ml}$ & 4.9 & 0.2 & 0.0133 & 2.0 & 501.2 & $\begin{array}{l}\text { tricyclic antidepressant; blocks the } \\
\text { reuptake of serotonin and norepinephrine } \\
\text { in the brain }\end{array}$ \\
\hline & Amitriptyline & $10 \mathrm{mM}$ & 4.1 & 1.5 & 0.0056 & 0.5 & 12.6 & $\begin{array}{l}\text { antidepressant; serotonin> } \\
\text { norepinephrine }>>\text { dopamine reuptake } \\
\text { inhibitor. }\end{array}$ \\
\hline & Promazine & $2 \mathrm{mg} / \mathrm{ml}$ & 3.5 & 0.9 & 0.0001 & & & $\begin{array}{l}\text { antipsychotic; D2R antagonistThis G- } \\
\text { protein coupled receptor inhibits adenylyl } \\
\text { cyclase activity }\end{array}$ \\
\hline & Moricizine & $2 \mathrm{mg} / \mathrm{ml}$ & 3.3 & 0.5 & $8.1 \times 10^{-10}$ & & & voltage-gated sodium channel blocker \\
\hline & Desipramine & $10 \mathrm{mM}$ & 3.2 & 1.6 & 0.0360 & $150-250$ & 100 & antidepressant \\
\hline & Methotrimeprazine & $2 \mathrm{mg} / \mathrm{ml}$ & 3.2 & 0.3 & 0.0249 & & & $\begin{array}{l}\text { mACh: anticholinergic effects, inhibition of } \\
\text { extrapyramidal side effects }\end{array}$ \\
\hline & Piperacetazine & $2 \mathrm{mg} / \mathrm{ml}$ & 3.1 & 1.1 & 0.0039 & & & a1-adrenergic: hypotension, tachycardia \\
\hline & Trifluoperazine & $\begin{array}{l}5 \mathrm{mg} / \mathrm{ml} \\
10 \mathrm{mM}\end{array}$ & $\begin{array}{l}-1.8 \\
-2.0\end{array}$ & $\begin{array}{l}0.5 \\
0.3\end{array}$ & $\begin{array}{c}0.0001 \\
3.4 \times 10^{-14}\end{array}$ & 63.1 & & calmodulin inhibitor; inhibits D1R and D2R \\
\hline & Triflupromazine & $2 \mathrm{mg} / \mathrm{ml}$ & -2.0 & 0.3 & $3.2 \times 10^{-12}$ & & & $\begin{array}{l}\text { antipsychotic; dopamine D2-receptor } \\
\text { antagonist }\end{array}$ \\
\hline & Hycanthone & $2 \mathrm{mg} / \mathrm{ml}$ & -2.0 & 0.2 & $3.3 \times 10^{-16}$ & & & Antischistosomal; \\
\hline & Zuclopenthixol & $2 \mathrm{mg} / \mathrm{ml}$ & -2.2 & 0.6 & 0.0001 & & & $\begin{array}{l}\text { antipsychotic; dopamine D1- and D2- } \\
\text { receptor antagonist }\end{array}$ \\
\hline & Thiethylperazine & $2 \mathrm{mg} / \mathrm{ml}$ & -2.4 & 0.4 & $5.3 \times 10^{-12}$ & & & antihistamines; \\
\hline
\end{tabular}

Figure 2. Tricyclic compounds with known physiologic effects but poorly defined or multiple signaling mechanisms. The list of trimeprazine analogs (tricyclic compounds) that increased IRS2 mRNA expression more than the 95th percentile or less than the 5th percentile $(P<0.05)$ in isolated human islets. The reported binding affinity toward $\mathrm{H} 1 \mathrm{R}$ or $\alpha 1$-adrenergic was obtained from The Binding Database (http:// www.bindingdb.org/bind/index. jsp). $\alpha 1 a, \alpha 1$-adrenergic receptor; conc, concentration; H1R, histamine $\mathrm{H} 1$ receptor; mAChR, muscarinic acetylcholine receptor; SE, standard error. 
tuted basic amine moiety. Most of the compounds act as antihistamines or antipsychotics by competitive inhibition of various GPCRs. The preferred tricyclic cores for induction of IRS2 included phenothiazines (e.g., trimeprazine, ethopropazine, and promazine) or dibenzocycloheptene (e.g., nortriptyline and amitryptyline). The antidepressant maprotiline - an anoanthracene tetracyclic with a 6,6,6 tricyclic core that has a fourth bridging 6-membered ring and the same 3-carbon linker to its basic amine side chain - also strongly increased IRS2 expression. Thus, our screening data suggest a general preference for unsubstituted phenothiazines for IRS2 upregulation, with the following substituents being progressively less favorable: $\mathrm{Cl}>\mathrm{COMe}>\mathrm{CN}>\mathrm{CF} 3>\mathrm{SMe}>\mathrm{SOMe}>\mathrm{SO}_{2} \mathrm{NMe}_{2}$. Of the structures that show downregulation of IRS2, an $\mathrm{N}$-alkyl piperazine moiety was noted along with Aryl CF3 substituents. Further testing with a broader set of compounds is warranted to draw definitive conclusions about structure activity relationships for either up- or downregulation of IRS2 in human islets and $\beta$ cells.

Effect of IRS 2 modulators on murine $\beta$ cell mass. Previous work shows that IRS2 promotes the growth, function, and survival of murine $\beta$ cells $(21,22)$. Although investigation of all the compounds identified by our screen was beyond the scope of the study, we investigated whether a small, structurally diverse subset of nontoxic compounds increased IRS2 mRNA concentrations in isolated human islets from 3 different donors. Forskolin (adenylate cyclase activator), YC-1 (a phosphodiesterase inhibitor), and zardaverine (phosphodiesterase type 11 inhibitor) had the strongest effect on increasing IRS2 over the widest concentration range (Figure 1, C, F, and G). K252A (calcium/calmodulin-dependent protein kinase 2 inhibitor) and trimeprazine (a representative tricyclic antihistamine) showed a 2-fold effect over a narrower concentration range (Figure 1, D and E). Next, we treated healthy 8-week-old C57BL/6J mice by daily i.p. injection for 3 weeks with zardaverine, exendin-4, forskolin, K252A, YC-1, or trimeprazine (Figure 1H). Mice treated with an equal amount of DMSO or sterile saline (control, depending on the solubility of compound) were used as negative controls, and exendin-4-treated mice served as the positive control, because exendin- 4 was shown previously to promote mouse $\beta$ cell growth (23). After 3 weeks of treatment, the average islet area was determined from multiple pancreas sections $(10-\mu \mathrm{m})$ as previously described (22). Whereas zardaverine had a comparatively strong effect on IRS2 expression in human islets, it had a small and insignificant effect on mouse islet area (Figure $1 \mathrm{H})$. By contrast, the other tested compounds, including exendin-4, significantly increased islet area (Figure $1 \mathrm{H})$. Trimeprazine was the most potent compound tested, as it increased islet area by 2 -fold (Figure $1 \mathrm{H}$ ). Moreover, after 7 daily injections of trimeprazine, islets isolated from mice displayed a 2-fold higher concentration of IRS2 protein (Figure 1, I and J). We selected trimeprazine (10 $\mathrm{mg} / \mathrm{kg}$ ) as a representative tricyclic compound for further analysis.

Specificity of trimeprazine. Trimeprazine is a first-generation tricyclic antihistamine containing the same tricyclic core as phenothiazine antipsychotics such as chlorpromazine; however, it is used mainly as an antihistamine, an antipruritic, a sedative, or an antiemetic (24-26). Trimeprazine is best known as an H1R antagonist, but it can behave as a partial agonist (see below). We investigated the molecular specificity of trimeprazine using a well-defined, commercially available assay system, the Cellular Functional GPCR Profile (Cerep Inc.), which is composed of 30 heterologous cell lines engineered to express a GPCR that might interact with trimeprazine (27). The engineered cell lines were incubated with trimeprazine (20 mg/1) alone to identify agonist activity. Fourteen of the tested GPCRs were stimulated by trimeprazine, 5 of which responded to at least $50 \%$ of the level stimulated by the ideal agonist, including OPRK1 (opioid receptor $\kappa 1 \rightarrow \mathrm{CAMP}$ ); OPRM1 (opioid receptor $\mu 1 \rightarrow \mathrm{cAMP}$ ); TACR1 (tachykinin receptor 1 ; substance P receptor $\rightarrow \mathrm{Ca}^{2+}$ ); HRH1 (histamine receptor $\mathrm{H} 1 \rightarrow \mathrm{Ca}^{2+}$ ); and CHRM5 (cholinergic receptor, muscarinic $5 \rightarrow \mathrm{Ca}^{2+}$ ) (Figure 3A). As expected, trimeprazine antagonized most of the tested GPCRs by inhibiting the response to a cognate agonist by more than $50 \%$ (Figure $3 \mathrm{~B}$ ). Thus, trimeprazine was not a specific partial agonist or antagonist of the H1R, but also blocked and/or partially activated several GPCRs that signal through inositol trisphosphate (IP3), IMP (electrical impedance), cAMP or $\mathrm{Ca}^{2+}$-mediated mechanisms. Compared with the GLP1 receptor, some of the tested GPCRs are expressed above the 50th percentile in pancreatic islets (Figure 3C). Moreover, the expression of 3 of the tested GPCRs correlated positively (OPRD1, CHRM4, and CCKAR), whereas 4 (including H1R) correlated negatively with IRS2 expression in human islets (Figure $3 \mathrm{D}$ ). Thus, the signaling mechanism of trimeprazine for the promotion of IRS2 expression in islets can be complex, and more work is needed to establish whether upregulation of IRS2 is mediated by partial activation of H1R, or whether trimeprazine acts through other GPCRs in islets and $\beta$ cells.

Trimeprazine promotes CREB phosphorylation and modulates gene expression in human islets. Many GPCR-signaling cascades and transcription factors might generate a composite signal to modulate IRS2 expression in 
A (Agonist)

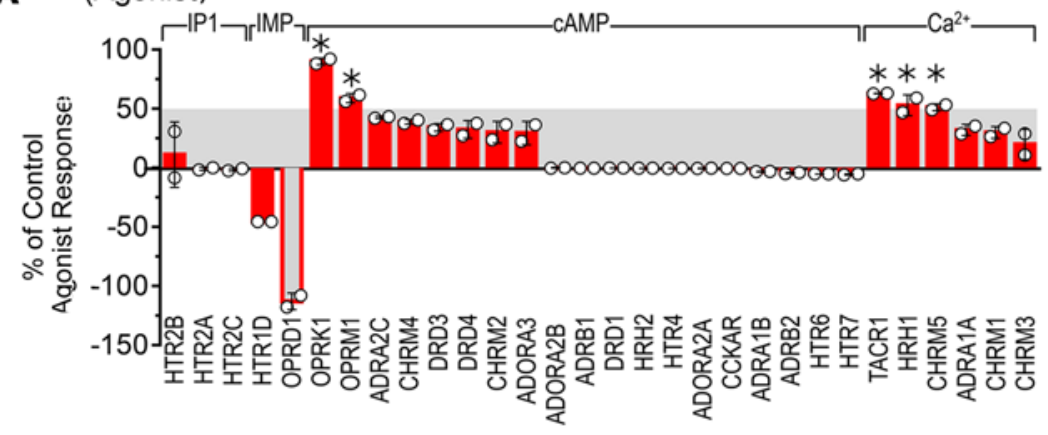

B (Antagonist)

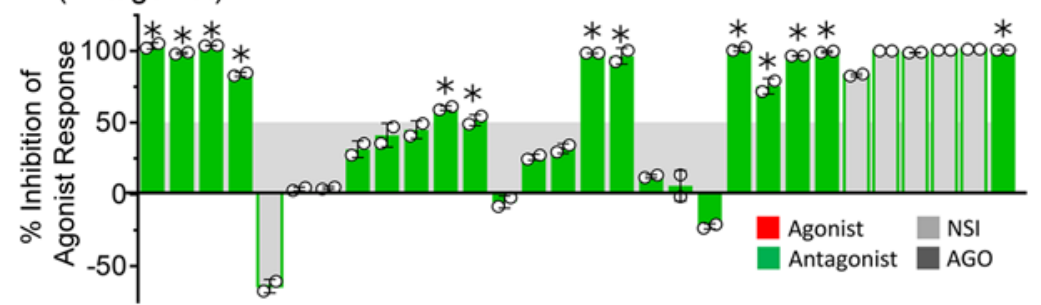

C (Relative Islet Expression)

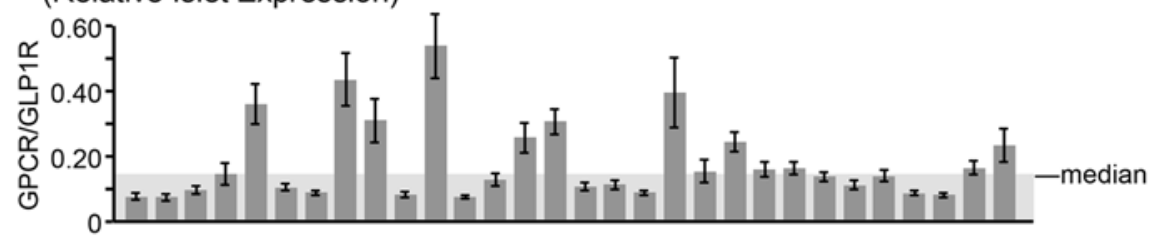

D (Correlation)

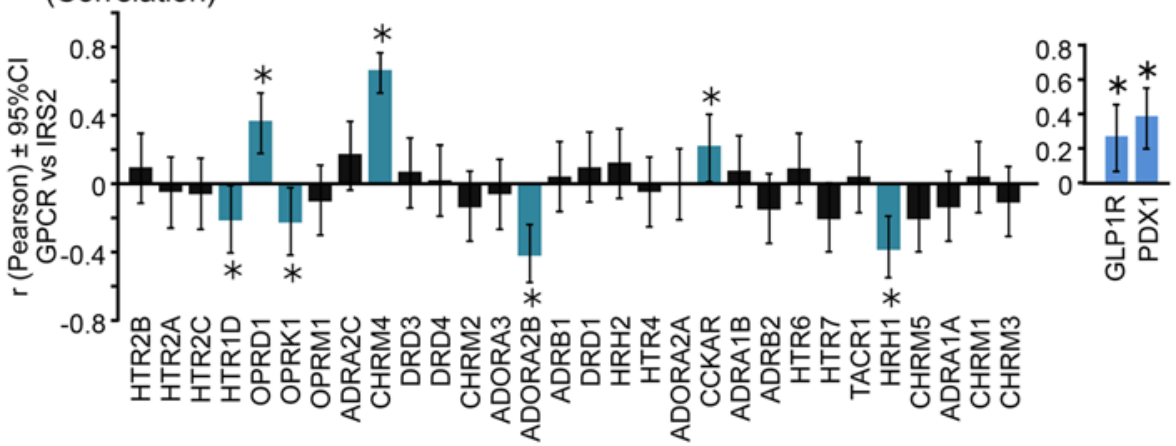

Figure 3. Trimeprazine tartrate $(\mathbf{2 0} \mathrm{mg} / \mathrm{l})$ was analyzed using the Cellular Functional GPCR Profile covering 30 different GPCRs. Agonist (A) and antagonist (B) measurements were conducted in duplicate, and the data points are shown as white circles with a bar for the SD. Results showing a stimulation or an inhibition higher than $50 \%$ (above gray bar) were considered significant $\left(^{*}\right.$ ) on the basis of historical data at Cerep. Measurements between $25 \%$ and $50 \%$ indicate weak-to-moderate effects that were not considered significant. The receptors are grouped by the assay read-out: IP1 (inositol phosphate 1); IMP (electrical impedance); cAMP (cyclic adenosine monophosphate); or Ca²+. "NSI" indicates that the test compound interfered nonspecifically in the assay judged, because the signal observed was very different from the signal of the reference agonist, suggesting that the compound acts through a different pathway. "ACO" indicates that the test compound induced at least a $25 \%$ agonist or agonist-like effect at this concentration, so further addition of the reference agonist could not produce a full response (partial agonist), which resulted in an apparent inhibition. (C) The average relative expression of the selected GPCRs taken from publicly available Affymetrix CEL files (http://www.ncbi.nlm.nih.gov/geo/query/acc.cgi?acc=GSE50398) was normalized against GLP1R expression. The expression profiles were analyzed using RMA16 in GeneSpring, version 12.6. The GPCR/GLP1R below the median is highlighted in the gray box. (D) ${ }^{*} P<0.05$. Pearson's correlation coefficient for the expression of each GPCR against IRS2 expression calculated using Analyze-it. The 2-sided 95\% Cls were determined by Fisher's Z test. Inset shows the correlation coefficient between IRS2 and either GLP1R or PDX1. HTR2B, 5-hydroxytryptamine (serotonin) receptor 2B; HTR2A, 5-hydroxytryptamine (serotonin) receptor 2A; HTR2C, 5-hydroxytryptamine (serotonin) receptor 2C; HTR1D, 5-hydroxytryptamine (serotonin) receptor 1D; OPRD1, opioid receptor $\delta 1$; OPRK1, opioid receptor $\kappa 1$; OPRM1, opioid receptor $\mu 1$; ADRA2C, adrenergic $\alpha-2 C$ receptor; CHRM4, cholinergic receptor muscarinic 4; DRD3, dopamine receptor D3; DRD4, dopamine receptor D4; CHRM2, cholinergic receptor muscarinic 2; ADORA3, adenosine A3 receptor; ADORA2B, adenosine A2b receptor; ADRB1, adrenergic $\beta$-1 receptor; DRD1, dopamine receptor D1; HRH2, histamine receptor H2; HTR4, 5-hydroxytryptamine (serotonin) receptor 4; ADORA2A, adenosine A2a receptor; CCKAR, cholecystokinin A receptor; ADRA1B, adrenergic $\alpha$-1B receptor; ADRB2, adrenergic $\beta$-2 receptor surface; HTR6, 5-hydroxytryptamine (serotonin) receptor 6; HTR7, 5-hydroxytryptamine (serotonin) receptor 7 (adenylate cyclase-coupled); TACR1, tachykinin receptor 1; HRH1, histamine receptor H1; CHRM5, cholinergic receptor, muscarinic 5; ADRA1A, adrenergic $\alpha$-1A receptor; CHRM1, cholinergic receptor muscarinic 1; CHRM3, cholinergic receptor muscarinic 3; IRS2, insulin receptor substrate 2. 

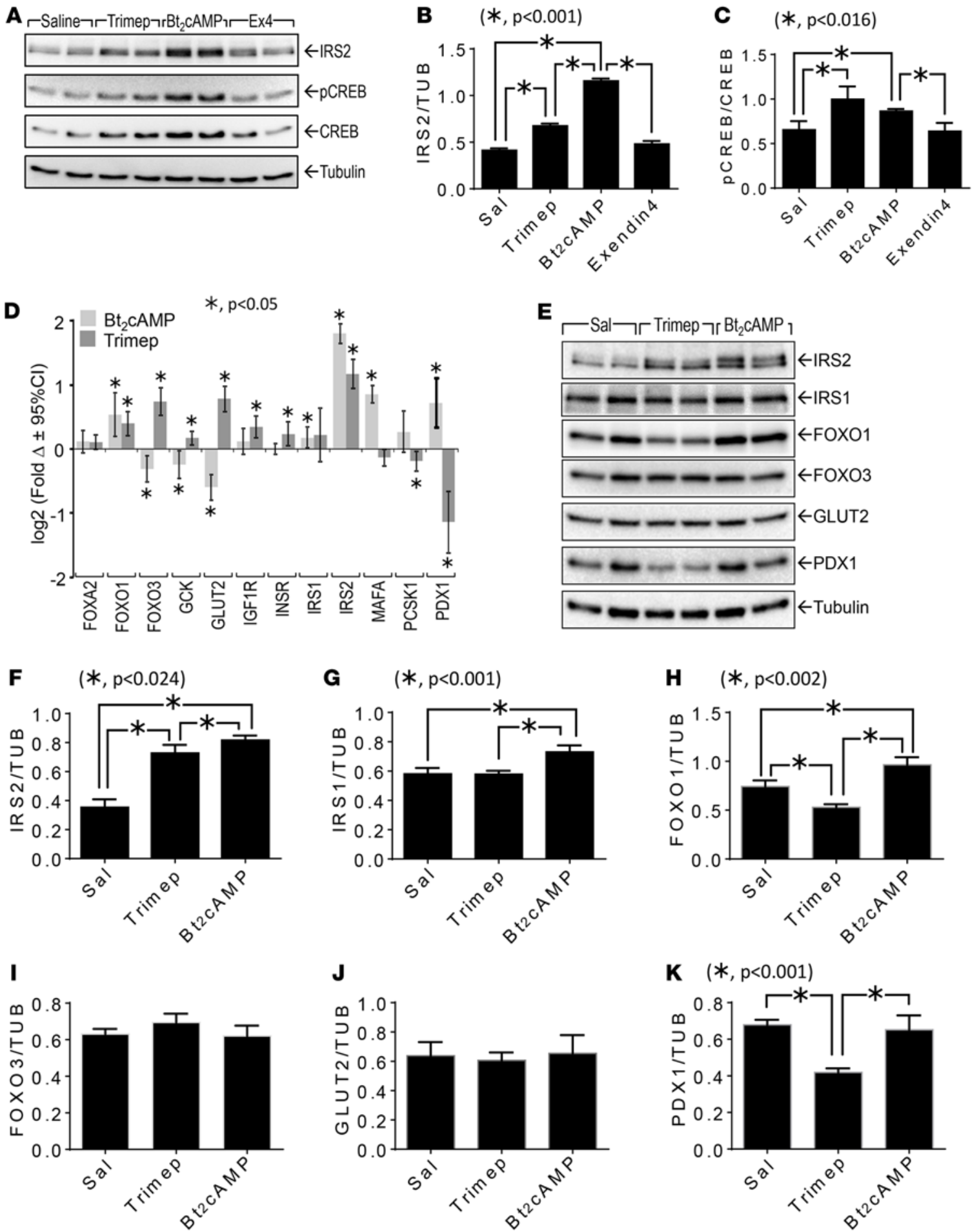

Figure 4. Effect of trimeprazine or Bt2cAMP on gene or protein expression in isolated human islets. (A-C) Human islets ( 100 islets) were treated with or without trimeprazine $(20 \mu \mathrm{g} / \mathrm{ml}), \mathrm{Bt}_{2} \mathrm{CAMP}(1 \mathrm{mM})$, or exendin-4 $(250 \mathrm{nM})$ for 24 hours, and the islet extracts were resolved by immunoblotting. The band intensity for total IRS2 intensity (B) was normalized against tubulin; phosphorylated CREB (pCREB) (C) was normalized against total CREB. The mean \pm SEM was determined from 2 data points in 2 experiments; "** indicates the Bonferroni-corrected $P$ value (in the indicated range, $P<0.05$ was significant) determined by a generalized linear model (SPSS, version 23). (D) Human islets ( 100 islets) were treated with or without trimeprazine (20 $\mu$ / $\mathrm{ml}$ ) or $\mathrm{Bt}_{2}$ CAMP ( $1 \mathrm{mM}$ ) for 5 hours, and expression of the indicated genes was measured with a QuantiGene 2.0 Plex Assay Kit $(n=6)$. This experiment was repeated with islets from 4 different donors, and the average $\log _{2}$ (fold $\left.\Delta\right) \pm 95 \% \mathrm{Cl}$ relative to the DMSO control for each gene is shown; "*" indicates the Bonferroni-corrected $P$ value of less than 0.05 , determined by GLM using SPSS, version 23 . (E-K) Islets ( 100 islets) were treated with trimeprazine (20 $\mu$ / $\mathrm{ml}), \mathrm{Bt}_{2}$ CAMP $(1 \mathrm{mM})$, or saline for 24 hours, followed by immunoblot analysis of the indicated proteins in islet extracts. The band intensity of the indicated proteins was normalized against tubulin intensity. The mean \pm SEM was determined from 2 data points in 2 experiments; "** indicates the Bonferroni-corrected $P$ value (in the indicated range, $P<0.05$ was significant) determined by GLM (SPSS, version 23 ). $P$ values greater than 0.05 were omitted from the figure. cAMP, cyclic AMP; Ex4, exendin-4; Sal, saline; Trimep, trimeprazine; TUB, tubulin. 
islets and $\beta$ cells. CREB phosphorylation is a possible mechanism, as it is downstream of cAMP- and $\mathrm{Ca}^{2+}$ mediated protein kinases and is known to increase IRS2 expression in $\beta$ cells (12). We investigated CREB phosphorylation in human islets treated with trimeprazine or $\mathrm{Bt}_{2} \mathrm{CAMP}$. As expected, $\mathrm{Bt}_{2} \mathrm{CAMP}$ increased CREB phosphorylation and the IRS2 concentration in human islets; trimeprazine showed a similar effect (Figure 4, A-C). However, exendin-4 had no effect on either response, which was consistent with its inactivity in our chemical screen.

To determine whether trimeprazine and $\mathrm{Bt}_{2} \mathrm{cAMP}$ have similar effects on gene expression, we treated human islets for 4 hours with each compound and compared the expression levels of various genes important for $\beta$ cell function using the QuantiGene 2.0 Plex Assay. As expected, trimeprazine and Bt ${ }_{2} \mathrm{AMP}$ increased the concentration of IRS2 mRNA by 2- or 3-fold, respectively (Figure 4D). $\mathrm{Bt}_{2} \mathrm{cAMP}$ also increased FOXO1, MAFA, PDX1, and IRS1 expression, whereas it reduced the expression of FOXO3, GCK, and GLUT2. Trimeprazine also increased FOXO1 expression; however, it also increased the expression of FOXO3, GCK, GLUT2, IGF1R, and INSR, while it reduced the expression of MAFA, proprotein convertase subtilizing/kexin type 1 (PCSK1), and PDX1. The pattern of trimeprazine-modulated gene expression (increased IRS2, FOXO1, and FOXO3A, but reduced PDX1 and GLUT2 expression) was reflected by similar, but not identical, changes in the protein concentrations relative to tubulin (Figure 4, $\mathrm{E}-\mathrm{K})$. Thus, except for IRS2 and $\mathrm{FOXO} 1, \mathrm{Bt}_{2} \mathrm{cAMP}$ was not an exact mimetic of trimeprazine-regulated gene expression, which might reflect a complex mechanism of trimeprazine action through pathways in addition to that of CAMP.

Effect of trimeprazine on diabetes in $P d x 1^{+/-}$mice. Nuclear $\mathrm{Pdx} 1$ plays an important role in pancreas development and adult $\beta$ cell function (28). Previous work shows that Irs 2 signaling might promote Pdx1 nuclear signaling by inhibiting nuclear FOXO1 (Irs2 $\rightarrow$ PI3K $\rightarrow$ AKT $1 F O X O 1^{\text {Nuc }} \nmid P d x 1^{\text {Nuc }}$ ) $(29,30)$. PDX1 levels can be increased by FOXO1 induction or degraded by GSK3 $\beta$-mediated phosphorylation $(31,32)$. Enforced expression of $\mathrm{Pdx} 1$ can restore islet and $\beta$ cell function in Irs $2^{-1-}$ mice (30). Unexpectedly, while trimeprazine increased IRS2, it also reduced Pdx1 mRNA and protein levels (see Figure 4, E and K, above). We therefore investigated whether trimeprazine improved $\beta$ cell function and glucose tolerance in $P d x 1^{+/-}$mice. As previously reported (30), our $P d x 1^{+/-}$mice were glucose intolerant by 5 weeks of age (Figure $5, \mathrm{~A}$ and B). These mice, along with their WT littermates, were treated between 5.5 and 8.5 weeks of age with daily i.p. injections of trimeprazine $(10 \mathrm{mg} / \mathrm{kg} /$ day) or sterile saline. Glucose intolerance persisted in the salinetreated $P d x 1^{+/-}$mice until the experiment was terminated at 8.5 weeks (Figure 5, A and B). Although 3 weeks of trimeprazine treatment had no effect on the median glucose tolerance in control mice, glucose tolerance in the $P d x 1^{+/-}$mice was almost completely normalized and statistically indistinguishable from that of the controls (Figure 5, A and B). Consistent with these results, HOMA2 \%B was reduced significantly in $P d x 1^{+/-}$mice, whereas trimeprazine increased HOMA2\%B in $P d x 1^{+/-}$mice to within the normal range of the saline-treated controls (Figure 5C).

Effect of trimeprazine on Irs $2^{-1-}$ mice. Trimeprazine might promote $\beta$ cell function through multiple mechanisms. To determine whether its effects are mediated, at least in part, through IRS2, we treated 6-week-old control or Irs $2^{-/}$mice without or with trimeprazine $(10 \mathrm{mg} / \mathrm{kg} /$ day $)$ in sterile saline for 3 weeks. As shown previously, Irs $2^{-1-}$ mice developed diabetes (fasting glucose $>200 \mathrm{mg} / \mathrm{dl}$; random fed glucose $\sim 600 \mathrm{mg}$ / dl) by 8 weeks of age and died with hyperglycemia between 10 and 15 weeks of age (21). Cox regression analysis showed that daily trimeprazine injections did not significantly alter the onset of diabetes (Figure $6 \mathrm{~A})$. Consistent with this result, trimeprazine had no effect on glucose tolerance in Irs2 $2^{-1-}$ mice, as it did not restore the normal response to i.p. glucose injections $(2 \mathrm{~g} / \mathrm{kg})$ in diabetic Irs $2^{-1-}$ mice (Figure 5 , A and B). Moreover, trimeprazine did not change insulin sensitivity in control or Irs $2^{-1-}$ mice, as measured by an insulin tolerance test (Supplemental Figure 1).

Irs2 is essential for $\beta$ cell growth and survival $(9,17)$. HOMA2\%B showed that trimeprazine did not restore normal $\beta$ cell function in Irs $2^{-/-}$mice compared with the positive effect observed in $P d x 1^{+/-}$mice (Figure 5C). The insulin-positive $\beta$ cell area percentage increased significantly in pancreas sections from control mice treated for 3 weeks with trimeprazine compared with that seen in sections from saline-treated control mice (Figure 6, B and C). By contrast, the insulin-positive $\beta$ cell area percentage was reduced significantly by $50 \%$ in 8 -week-old Irs2 $2^{-1-}$ mice, and 3 weeks of trimeprazine treatment started at 5 weeks of age failed to increase the $\beta$ cell area percentage to within the normal range (Figure 6, B and C). Next, we treated control and Irs $2^{-/-}$mice with BrDU to estimate $\beta$ cell proliferation with or without trimeprazine treatment. WT mice treated with trimeprazine displayed 2-fold more BrdU incorporation than did saline- 

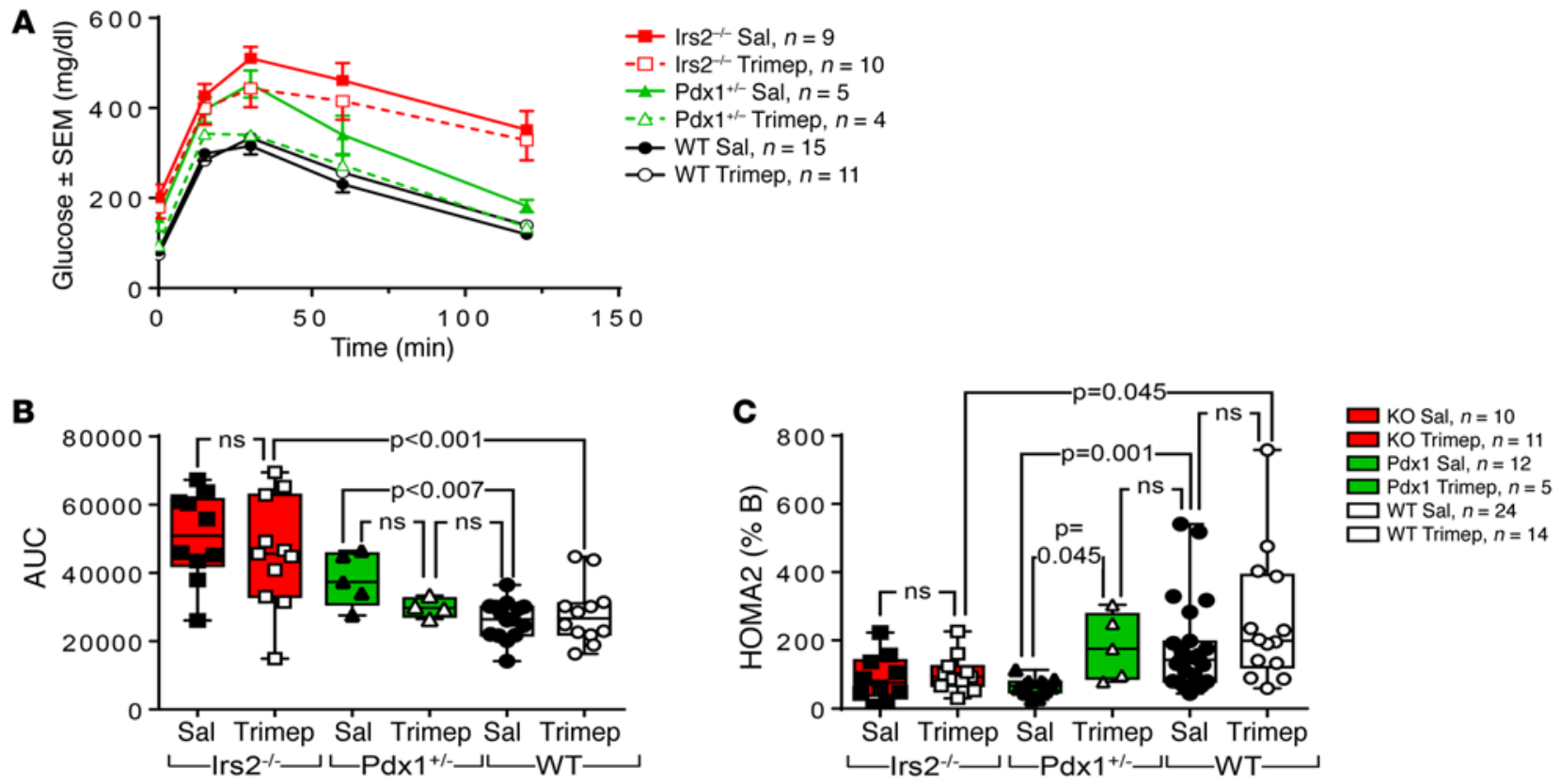

Figure 5. Effect of trimeprazine on WT, Irs $2^{-/-}$, or $P d x 1^{1^{+-}}$mice treated with i.p. injections of $10 \mathrm{mg} / \mathrm{kg}$ trimeprazine or without (saline) once a day for 3 weeks. (A) IPGTT in C57BL/6 mice treated between 5.5 and 8.5 weeks of age. The mean \pm SEM is shown for each data point. (B) AUC (from A) was calculated (Medcalc, version 13.3.3) and analyzed by a GLM (SPSS, version 23), with genotype and drug treatment as interacting factors. Bonferroni-corrected $P$ values of less than 0.05 were considered significant. (C) HOMA2 \%B was calculated using fasting glucose and insulin concentrations determined with the indicated experimental mice. Data were analyzed by a GLM, with genotype and drug treatment as interacting factors. Bonferroni-corrected $P$ values are shown; a $P$ value of less than 0.05 was considered statistically significant. Sal, saline; Trimep, trimeprazine.

treated control mice; however, Irs $2^{-1-}$ mice failed to incorporate more BrDU during trimeprazine treatment (Figure 6, D and E).

Next, we investigated the effect of trimeprazine on $\mathrm{Pdx} 1$ nuclear localization in $\beta$ cells from control and Irs $2^{-/-}$mice. Previous results showed that inhibition of nuclear FOXO1 in $\beta$ cells by gene KO or AKTmediated phosphorylation can promote nuclear localization of $\mathrm{Pdx} 1$ and rescue $\beta$ cell function in Irs $2^{-1}$ mice $(29,30)$. Pancreas sections from mice in each treatment group were immunostained with Abs against insulin and Pdx1 and stained with DAPI to distinguish the nuclei from the cytosol (Supplemental Figure 2). Nuclear Pdx1 localization greater than the median $\left(\mathrm{Pdx}^{>\mathrm{MED}}\right)$ was determined for each treatment group, as described in Methods (Supplemental Table 2). Three weeks of trimeprazine treatment significantly increased $\mathrm{Pdx} 1^{>\mathrm{MED}}$ localization in control islets, whereas trimeprazine had no effect on Irs $2^{-/-}$islets (Figure $6 \mathrm{~F}$ ). The effect of trimeprazine in increasing the number of $\beta$ cells with nuclear Pdx1 immunostaining above the median might explain in part its beneficial effect on $\beta$ cell function, even when Pdx1 expression was reduced.

Effect of trimeprazine on diabetes progression in anti-CD3 Ab-treated NOD mice. NOD mice develop diabetes owing to autoimmune destruction of pancreatic $\beta$ cells (33). Previous work showed that diabetic (blood glucose $>200 \mathrm{mg} / \mathrm{dl}$ ) NOD mice showed an acute and transient reduction in blood glucose levels during 5 consecutive days of $\alpha \mathrm{CD} 3$ injections; however, most of the mice returned to hyperglycemia within 5 days. The effect of $\alpha \mathrm{CD} 3$ to reduce hyperglycemia can be sustained when it is combined with other treatments such as exendin-4 or IL-1 $\beta$ antagonists (34-36). Moreover, transgenic Irs 2 postpones and reduces the onset of hyperglycemia in $\alpha \mathrm{CD} 3$-treated diabetic NOD mice (8). Given these results, we investigated the effect of trimeprazine on female diabetic NOD mice treated with $\alpha \mathrm{CD} 3$. Within 1 to 2 days after the onset of diabetes, $\alpha \mathrm{CD} 3$ acutely reduced the blood glucose concentration to within the normal range; however, as expected during the next 4 consecutive days of $\alpha \mathrm{CD} 3$ injections alone, the glucose concentration usually returned to within the diabetic range (Figure 7A). Moreover, during the 22-day experiment, blood glucose was reduced significantly by trimeprazine plus $\alpha \mathrm{CD} 3$ treatment compared with blood glucose levels with $\alpha \mathrm{CD} 3$ treatment alone (Figure 7, A and B). Only 2 of 15 mice treated with $\alpha \mathrm{CD} 3$ alone remained nondiabetic (blood glucose $<200 \mathrm{mg} / \mathrm{dl}$ ) when the experiment was terminated after 3 weeks (see the "+" symbols in Figure 7C). By contrast, only 2 of 16 diabetic NOD mice treated for 22 days with trimeprazine plus 
A

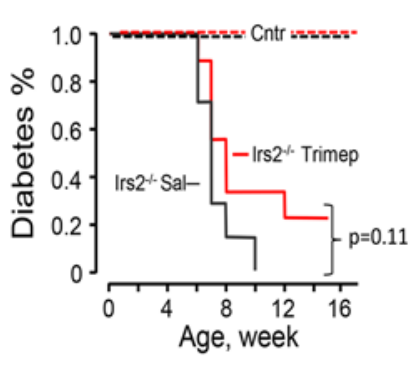

B

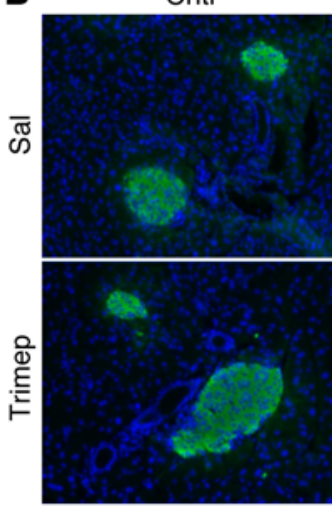

Irs2--

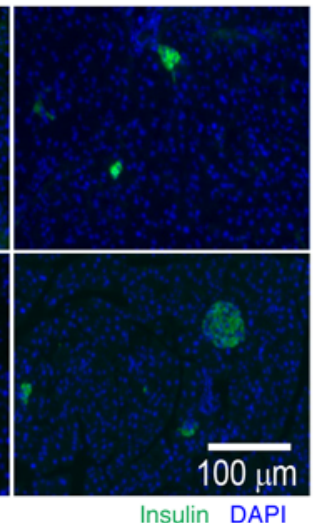

C
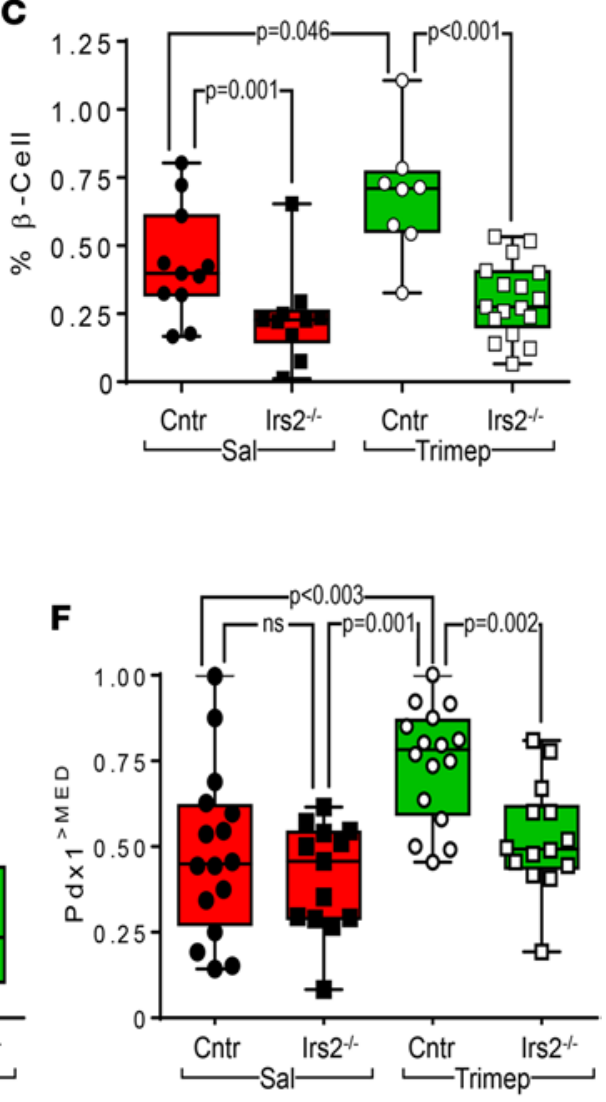

D

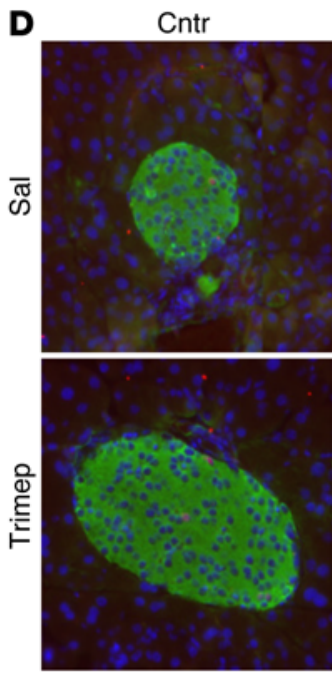

Irs2-1-

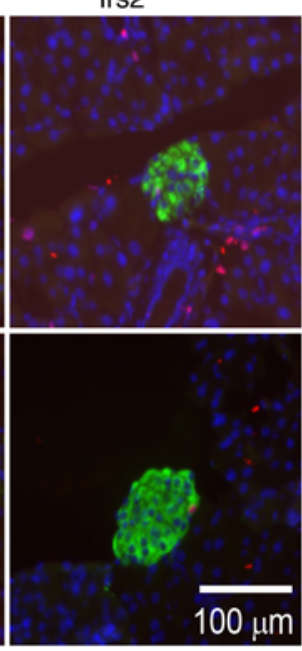

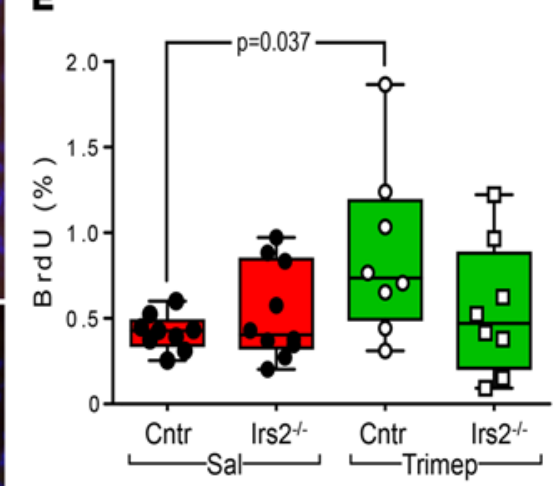

\section{E}

Insulin DAPI BrdU

Figure 6. Effect of trimeprazine on $\boldsymbol{\beta}$ cell function in Irs2 $\mathbf{2}^{-/-}$mice. (A) Cox regression analysis of diabetes onset (random blood glucose $>200 \mathrm{mg} / \mathrm{dl}$ ) in 15 Irs $2^{-1-}$ or control male mice treated without (saline, black line) or with $10 \mathrm{mg} / \mathrm{kg}$ trimeprazine (red line) once a day starting at 5 weeks of age until diabetes was diagnosed or the mice reached 16 weeks of age. (B) Control $(n=8)$ or $/ \mathrm{rs}^{-/-}(n=8)$ mice were treated for 3 weeks with or without $10 \mathrm{mg} / \mathrm{kg}$ trimeprazine, and pancreas sections were immunostained with Abs against insulin or stained with DAPI. (C) Two pancreatic sections were analyzed for each mouse, and at least 4 mice were analyzed in each experimental group to determine the percentage of $\beta$ cell area. The horizontal black bar in the box shows the median, and a GLM (IBM SPSS, version 23) was used to obtain Bonferroni-corrected $P$ values, with genotype and treatment as interacting factors. (D) BrdU incorporation in pancreas sections from 9-week-old control or $1 \mathrm{rs}^{-1-}$ mice treated between 6 and 9 weeks of age with or without daily trimeprazine $(10 \mathrm{mg} / \mathrm{kg})$. (E) Two pancreatic sections (10 $\times 10$ tiles) were analyzed for each mouse, and at least 4 mice were analyzed for each group to determine the percentage of BrdU-positive $\beta$ cells against the total number of insulin-positive $\beta$ cells. The black horizontal bar in the box shows the median, and a GLM was used to obtain the Bonferroni-corrected $P$ values, with genotype and treatment as interacting factors. (F) Control or Irs $2^{-/-}$mice were treated for 3 weeks with or without trimeprazine. Multiple pancreas sections from 2 or 3 mice in each experimental group were used to calculate Pdxi ${ }^{\text {MED }}$ (see Supplemental Table 2 and the Methods). Box plots show the distribution of Pdx1 ${ }^{>M E D}$, and a GLM was used to obtain the Bonferroni-corrected $P$ values, with genotype and treatment as interacting factors. Cntr, control; Sal, saline; Trimep, trimeprazine.

$\alpha \mathrm{CD} 3$ displayed blood glucose levels above $200 \mathrm{mg} / \mathrm{dl}$ (Figure 7C). Thus, trimeprazine plus $\alpha \mathrm{CD} 3$ significantly improved the recovery of diabetic NOD mice, as the median random blood glucose level reached the normal range by 22 days (Figure 7C). However, trimeprazine alone was unable to reduce the hyperglycemia of diabetic NOD mice (data not shown). HOMA2 \%B confirmed that trimeprazine plus $\alpha \mathrm{CD} 3$ significantly improved the apparent $\beta$ cell function (Figure 7D). Although the median $\beta$ cell mass was severely reduced in all diabetic NOD mice, trimeprazine-plus- $\alpha$ CD3-treated mice showed a 2-fold larger $\beta$ cell area when the experiment was terminated after 22 days (Figure 7, E-G). Moreover, trimeprazine plus $\alpha \mathrm{CD} 3$ treatment significantly increased BrDU incorporation into the NOD $\beta$ cells (Figure 7, E, F, and H). However, $\alpha \mathrm{CD} 3$ alone or trimeprazine plus $\alpha \mathrm{CD} 3$ treatment had no effect on the immune infiltrate characteristic of diabetic NOD mice (Figure 7, $\mathrm{E}$ and $\mathrm{F}$ ).

Effect of trimeprazine on human islets transplants in streptozotocin-induced diabetic mice. Transplantation of human islets under the kidney capsule of immune-compromised male mice is a useful technique to study 


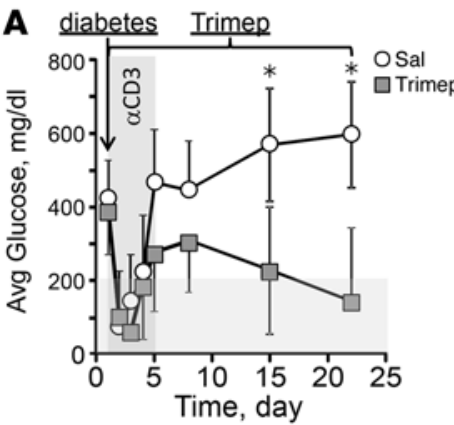

B
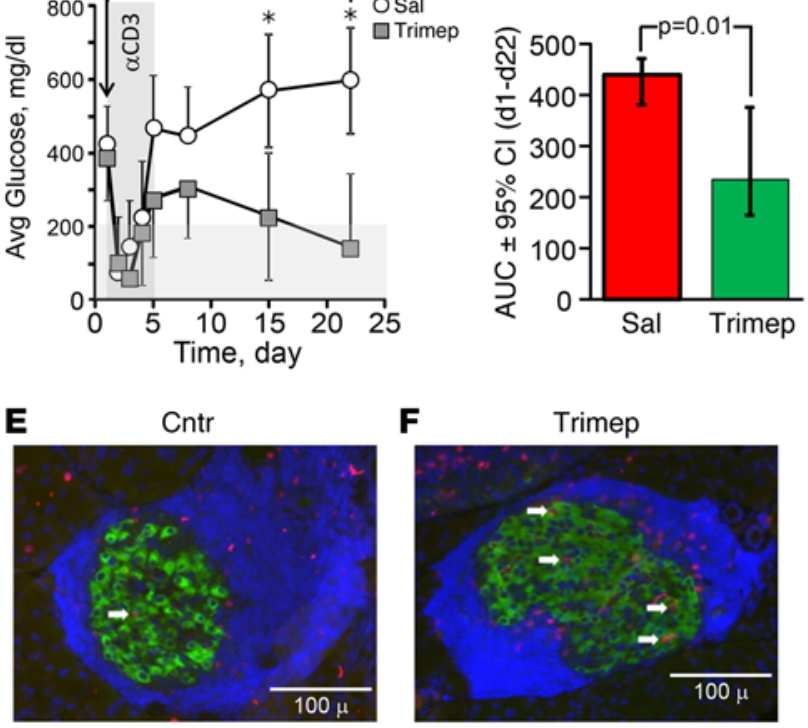

Insulin DAPI BrdU
$\mathbf{F}$

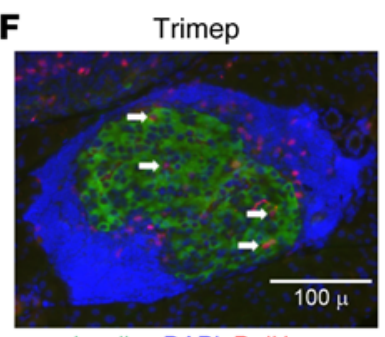

Insulin DAPI BrdU
C

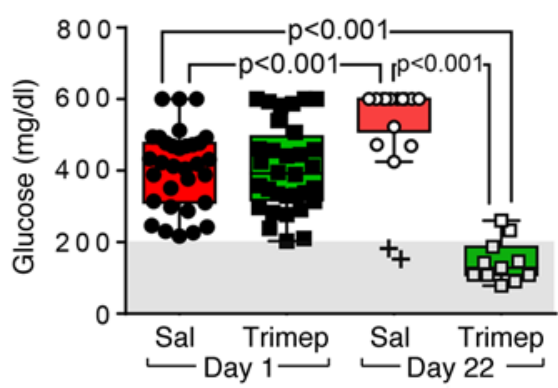

D

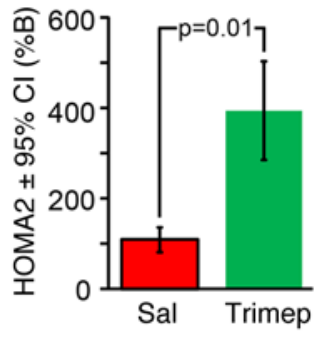

G

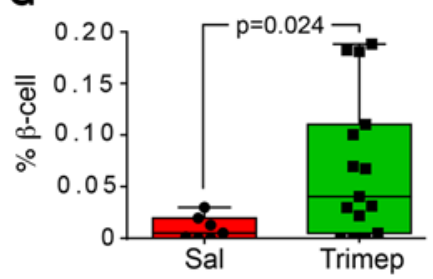

H

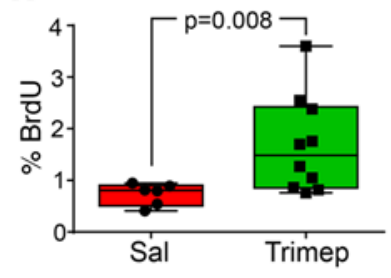

Figure 7. Metabolic and islet parameters from untreated or trimeprazine-treated diabetic NOD mice. (A) Random blood glucose levels (avg \pm SD, ${ }^{*} P<$ 0.01 ) in NOD mice from the day diabetes (blood glucose $>200$ for 2 consecutive days) was detected. Diabetic mice were treated with $\alpha$ CD 3 once a day for 5 days, with or without trimeprazine $(10 \mathrm{mg} / \mathrm{kg}$ ) once a day for 22 days. Each treatment group consisted of 16 mice on day 0 . (B) AUC calculated from the graph in A. (C) Random blood glucose levels on the first and second days that diabetes was detected (black squares and circles) before initiating treatment with (open squares on green background) or without (open circles on red background) trimeprazine. Box plots show the distribution, and the black horizontal line shows the median. "+" indicates outliers. A GLM (SPSS, version 23) was used to obtain the Bonferroni-corrected $P$ values. (D) HOMA2\%B was calculated to estimate $\beta$ cell function. The GLM was used to determine the mean value and obtain the Bonferroni-corrected $P$ values, with treatment as the factor. (E and F) Pancreas sections from 9 untreated and 15 trimeprazine-treated NOD mice ( 6 untreated mice of the 15 total were unavailable at 22 days because they were sacrificed when they developed fatal hyperglycemia before the end of the experiment). Dense blue staining around the islets shows lymphocyte nuclei (insulitis). Arrows show BrdU/insulin double-positive cells. The percentage of $\beta$ cell area (G) or the percentage of BrdU (H) calculated from the total number of insulin-positive $\beta$ cells was determined using IMARIS software. Box plots show the distribution, and the black horizontal bar shows the median. Comparisons were made by GLM, with treatment as the only factor. Avg, average; Sal, saline; Trimep, trimeprazine.

human $\beta$ cell function in an in vivo context $(37,38)$. To investigate the effect of trimeprazine in this model, we induced diabetes in beige SCID Fox Chase mice with a single high dose of streptozotocin (STZ). Three days later, when the blood glucose levels increased to $350 \mathrm{mg} / \mathrm{dl}$, we transplanted 800 human islets under the kidney capsule. These mice were divided randomly into 2 groups for daily treatment with or without trimeprazine until the experiment was terminated 75 days later. Although this low number of human islets reduced blood glucose levels below $200 \mathrm{mg} / \mathrm{dl}$ after 20 days of saline injections, it was not sufficient to reduce blood glucose levels to within the normal range of healthy Fox Chase mice (Figure 8A). By contrast, mice treated with daily trimeprazine reached the normal blood glucose concentration of healthy mice, which was significantly below the blood glucose concentration in saline-treated, human islet-transplanted mice between 50 and 75 days (Figure 8A). The body weights of untreated and trimeprazine-treated mice were indistinguishable at 75 days (Figure $8 \mathrm{~B}$ ), whereas glucose tolerance improved significantly with trimeprazine treatment (Figure 8, C and D). Murine insulin levels in fed mice were statistically indistinguishable in both experimental groups, suggesting that some endogenous islet function contributed to the glucose tolerance (Figure 8E). Although human insulin levels were lower in both experimental groups, trimeprazine treatment significantly increased human insulin levels by 2 -fold, and together, mouse and human insulin levels were elevated by 2 -fold during trimeprazine treatment (Figure 8F). Moreover, human c-peptide also increased significantly in blood from the trimeprazine-treated mice, confirming that the human islet transplants had better function (Figure $8 \mathrm{G}$ ). Compared with mice treated with saline alone, the volume of the insulin-positive tissue in the human islet grafts increased upon trimeprazine treatment (Figure $8 \mathrm{H}$ and Supplemental Figure 2). Although this increase was not significant by a GLM test (Figure $8 \mathrm{H}, P=0.074$ ), a 1-sided nonparametric Mann-Whitney $U$ test, assuming trimeprazine increased the graft size, reached significance $(P=0.046)$. Together, we conclude that trimeprazine has a positive effect on human islet function in STZ-induced diabetic mice. 

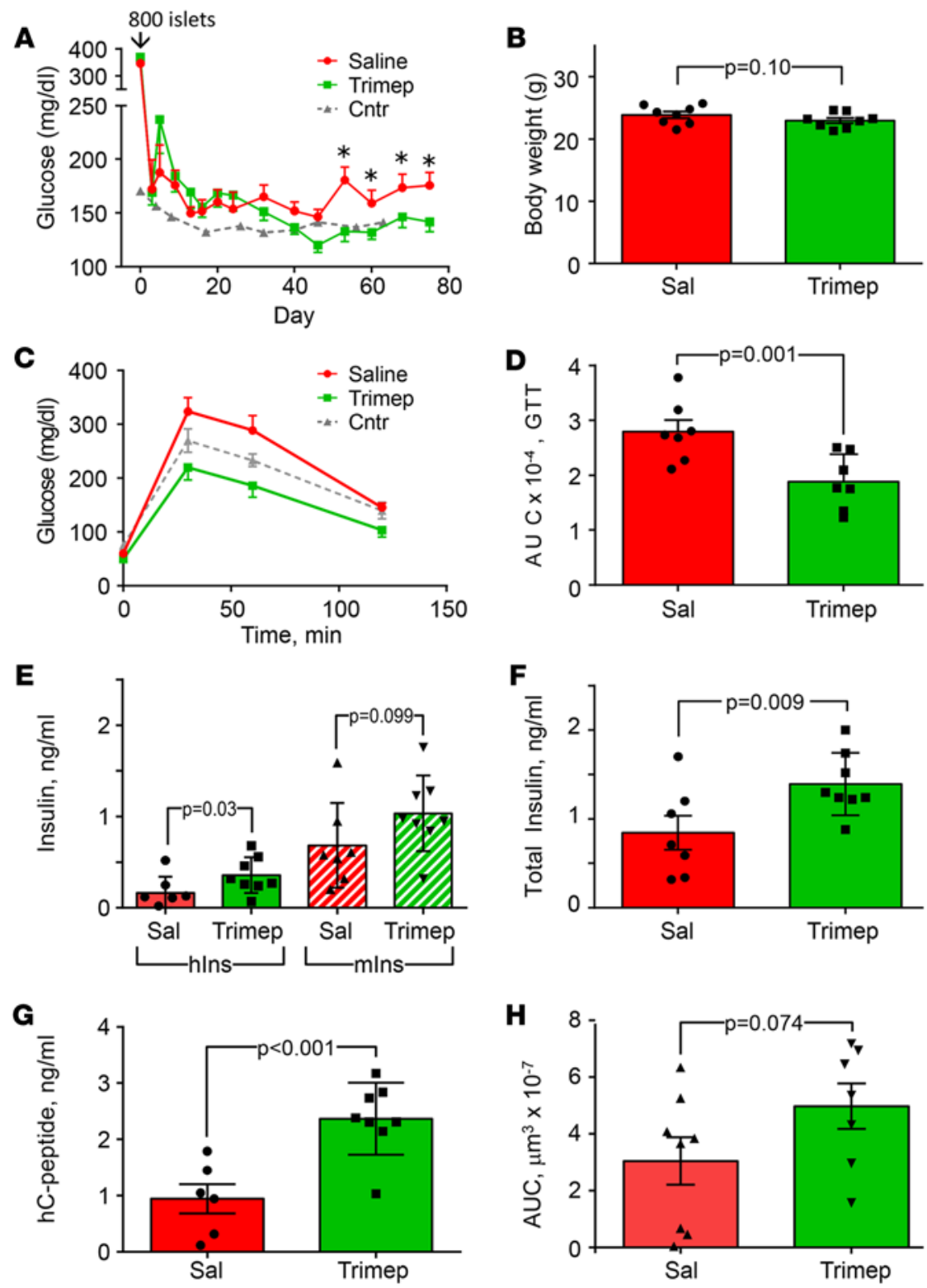
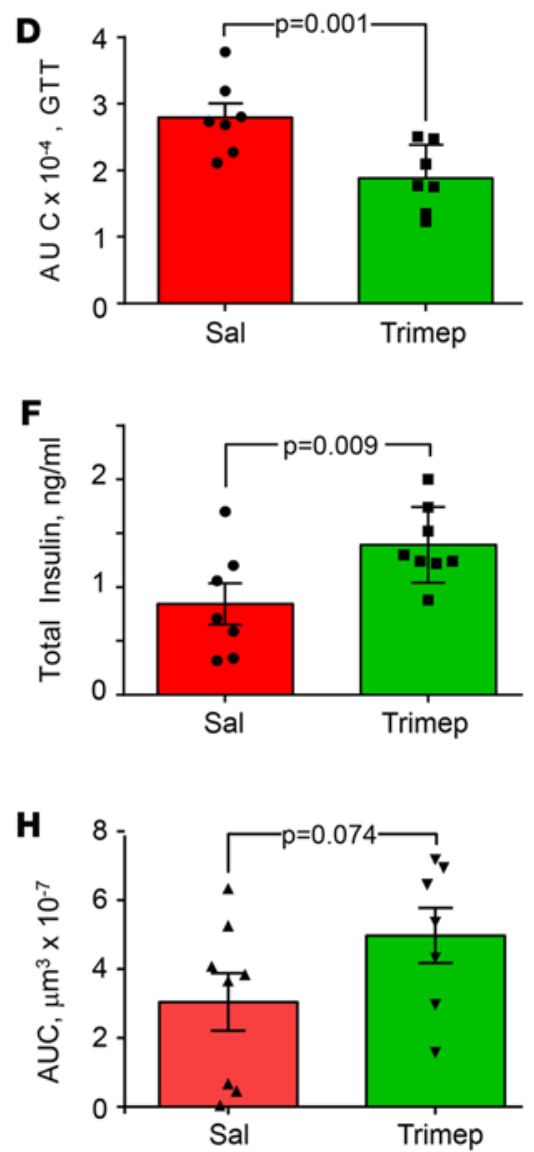

Figure 8. Metabolic and islet parameters from untreated or trimeprazine-treated STZ-induced diabetic male beige SCID Fox Chase mice transplanted with $\mathbf{8 0 0}$ human islets. (A) Glucose concentration measured at 8 am on the indicated day after transplantation and treated by daily injection of saline or trimeprazine. Blood glucose levels in healthy age-matched and untransplanted mice are shown for comparison (dashed line and black triangle). ${ }^{*} P<0.05$, by Student's $t$ test. (B) Body weight 75 days after islet transplantation; $P$ value, by Student's $t$ test.(C and $\mathbf{D})$ Glucose tolerance test 74 days after islet transplantation treated with (black square) or without (black circle) trimeprazine. Glucose tolerance test (CTT) in age-matched, control nondiabetic and untransplanted beige SCID Fox Chase mice is shown for comparison (black triangle). (E) Blood concentration of mouse (mlns) and human (hIns) insulin 75 days after islet transplantation. (F) Total insulin (mouse plus human) 75 days after islet transplantation. (C) Human c-peptide concentration in blood from untreated (Sal) or treated (Trimep) mice 75 days after islet transplantation. (H) AUC of specific human insulin immunostaining versus section position through the human islet grafts (see Supplemental Figure 3). Data were analyzed by GLM (SPSS, version 23), with drug treatment as the factor. The mean \pm SEM and $P$ values are shown. A $P$ value of less than 0.05 was considered significant. Cntr, control; hC-peptide, human c-peptide; hlns, human insulin; mlns, murine insulin; Sal, saline; Trimep, trimeprazine.

\section{Discussion}

Our chemical screen revealed at least 77 compounds that increase the expression of IRS2 mRNA in islets isolated from human cadavers. While the screen can be used for any gene of interest, we targeted IRS2, because previous work shows that it has an important role in $\beta$ cell growth, function, and survival, which might be beneficial for the treatment of diabetes (39). IRS2 is a highly regulated "gatekeeper" of islet and $\beta$ cell homeostasis, at least in part by linking heterologous inputs to the $\mathrm{PI} 3 \mathrm{~K} \rightarrow \mathrm{AKT}$ cascade that increases mTORC1 signaling, while inhibiting FOXO transcription factors and GSK3 $\beta$ (Supplemental Figure 4 and refs. 40, 41). Thus, the control of insulin/IGF1-regulated pancreatic $\beta$ cell function can be placed largely under the control of physiological IRS2 regulators, including glucose, incretins, and neuronal signals (Supplemental Figure 4 and refs. 42, 43).

We reasoned that the identification of compounds that increase the expression of IRS 2 in islets and $\beta$ cells could provide a rational strategy to improve glucose tolerance during metabolic or immunologic stress (44). A few of the identified compounds are known from previous work as having effects on glucose tolerance and insulin signaling, especially the PI3K inhibitors wortmannin and LY294002, which cause insulin resistance and stimulate FOXO nuclear function; the ATP-dependent $\mathrm{K}^{+}$channel blocker repaglinide, which can mimic the effect of elevated glucose; and the cAMP $\rightarrow$ PKA agonists IBMX and 
forskolin. However, the first-generation tricyclic antihistamines or antipsychotics represent a new group of IRS2 regulators with a poorly defined mechanism of action in $\beta$ cells. Regardless, the identification of 15 tricyclic analogs strongly supports the hypothesis that these compounds activate signaling cascades that can promote IRS2 expression in human and murine islets. Future work to identify the exact receptors that mediate this response might reveal novel strategies to maintain or restore $\beta$ cell function during the progression of diabetes in rodents and humans.

The regulated expression of IRS2 in $\beta$ cells might substitute for ligand regulation of the upstream insulin/IGF receptor kinases as in ordinary insulin/IGF target tissues $(45,46)$. Previous reports show that IRS2 expression is upregulated by glucose, incretins such as glucagon-like peptide 1 (GLP1), and other factors that increase cytosolic $\left[\mathrm{Ca}^{2+}\right]_{\mathrm{i}}$ or $[\mathrm{cAMP}]_{\mathrm{i}}$ in $\beta$ cells such as phosphodiesterase inhibitors (18). Thus, some plausible signaling cascades might include GascAMP $\rightarrow \mathrm{CREB} \rightarrow \mathrm{IRS} 2$; $\mathrm{Ca}^{2+} \rightarrow$ calcineurin $\rightarrow$ NFAT $\rightarrow$ IRS2; PI3K $\rightarrow$ AKT IFOXO1 $\rightarrow$ IRS2; or Gq $\rightarrow$ PLC $\beta \rightarrow$ IRS2 $(12-14,20,23,45)$. For example, glucose inhibits $\mathrm{K}^{+}$efflux to promote $\mathrm{Ca}^{2+}$-mediated insulin secretion, but glucose also increases IRS2 expression through $\mathrm{Ca}^{2+}$-stimulated NFAT $(10,13)$. Moreover, heterologous compounds such as repaglinide (also identified by our screen), which inhibit $\mathrm{K}^{+}$efflux and stimulate insulin secretion, might promote IRS2 expression through a $\mathrm{Ca}^{2+}$-mediated mechanism (47). Recent work with a $\mathrm{G}_{\mathrm{q}}$-coupled $\mathrm{M}_{3}$ (muscarinic acetylcholine) receptor, modified to be activated by biologically inactive ligands, shows directly that a $M_{3} \rightarrow G_{q}$ $\rightarrow \mathrm{Ca}^{2+} / \mathrm{PLC} \beta$ cascade upregulates IRS2 (17). Stimulation of $\mathrm{G}_{a s}$ by exendin- 4 activates adenylyl cyclase production of cAMP, which increases IRS2 expression through a CREB-mediated mechanism in murine $\beta$ cells (23). Although our screen failed to show that exendin-4 stimulated IRS2 expression in human islets, several other $\mathrm{CAMP} \rightarrow \mathrm{PKA}$ agonists induced IRS2 expression in our assay. It is possible that GLP1 receptors are inactivated by the isolation protocol or that islets recover incompletely in vitro.

Compounds that increase IRS2 expression might be useful, because IRS2 can be downregulated during physiological stress owing to the action of proinflammatory cytokines, GPCRs that suppress $\mathrm{Ca}^{2+}$ or cAMP signaling, and inhibition of FOXO1-mediated transcription by chronic hyperinsulinemia $(9,14,48$, 49). For example, some second-generation antipsychotic compounds, which antagonize the M3 receptor, disrupt insulin secretion and glucose homeostasis, which can progress to insulin resistance and diabetes (50). While compounds that modulate multiple GPCR cascades can have adverse effects such as metabolic disease, cardiac arrhythmias, neuronal stress, and $\beta$ cell failure, the judicious upregulation of IRS 2 in $\beta$ cells might have valuable therapeutic effects that would justify the search for $\beta$ cell targeted compounds.

Given the variety of compounds identified by our screen, investigation of all the possible mechanisms is beyond the scope of our work. To narrow our biological analysis, we focused on the tricyclic compounds, since many analogs including trimeprazine increase IRS2 mRNA in human islets. These compounds contain a common tricyclic pharmacophore with either 6,6,6 rings or 6,7,6 rings and a 2- to 3-atom side chain attached to a substituted basic amine moiety. Most of the compounds can act as antihistamines or antipsychotics by competitive inhibition of various GPCRs, especially H1R in the case of trimeprazine. Trimeprazine tartrate was selected as a representative tricyclic compound, because it has a favorable safety profile, minimal side effects, and increases the concentration of IRS2 mRNA and protein levels in human and mouse islets. However, trimeprazine displays sedative, antiserotonin, antispasmodic, and antiemetic properties (51). Consistent with the sedative effects of trimeprazine, mice became lethargic after their first full dose; however, this adverse effect could be avoided by starting the drug at a lower dosage and increasing it gradually over 3 days until a dose of $10 \mathrm{mg} / \mathrm{kg} /$ day was safely achieved.

Given the complex bioactivity of trimeprazine in the Cellular Functional GPCR Profile, we could not determine whether its antihistamine activity is an important signal for IRS2 expression. As expected, trimeprazine is a strong H1R antagonist, but it also antagonizes other heterologous GPCRs tested in the Cellular Functional GPCR Profile. Moreover, in the absence of ideal agonists, trimeprazine can be a partial agonist toward $\mathrm{H} 1 \mathrm{R} \rightarrow \mathrm{G}_{\mathrm{q}}$ and other tested GPCRs including OPRK1, OPRM1, TACR1, and CHRM5. Since mRNAs for all of these GPCRs can be detected in human islets, the composite signal generated by trimeprazine is difficult to know precisely. Regardless, trimeprazine can increase CREB phosphorylation, which reveals one way that it might increase IRS2 expression. Previous work shows that $\mathrm{CAMP} \rightarrow \mathrm{CREB}$ signaling increases IRS2 expression as a result of a consensus CRE half-site (TGACG) at -671 in the mouse promoter that is conserved in the human gene (12). Alternatively, partial activation of the H1R, the cholinergic receptor, the muscarinic 5 receptor (CHRM5), or the adrenergic $\alpha$-1A receptor (ADRA1A) by trimeprazine might also increase IRS2 expression through $\mathrm{Ca}^{2+} \rightarrow$ NFAT. Direct experiments to suppress the expression 
of H1R and other GPCRs are needed to establish trimeprazine-signaling mechanisms in human islets or $\beta$ cells, which might reveal new targets for future work. Whether modulation of these receptors generates signals, in addition to IRS2 expression, that promote islet and $\beta$ cell function needs to be investigated.

To determine whether trimeprazine increases islet size and $\beta$ cell content through IRS2 signaling, we used whole-body Irs $2^{-1-}$ mice that show normal glucose tolerance at birth, but deteriorate progressively between 6 and 12 weeks of age, owing to peripheral insulin resistance and $\beta$ cell loss (21). Importantly, transgenic expression of Irs 2 in the $\beta$ cells of Irs $2^{-/-}$mice restores mass and sufficient insulin secretion to maintain glucose tolerance (6). However, trimeprazine has no effect on $\beta$ cell content or glucose tolerance in Irs $2^{-/}$mice, suggesting that Irs2 signaling plays a role. While it is possible that the absence of Irs 2 has a dominant effect that cannot be overcome by trimeprazine-mediated signaling alone, the parsimonious explanation is that increased Irs 2 concentration mediates the effects of trimeprazine on $\beta$ cell function.

PDX1 is an important transcription factor for both pancreas development and mature $\beta$ cells, as it regulates downstream genes needed for $\beta$ cell growth and function (52). PDX1 haploinsufficiency diminishes the function of $\beta$ cells, which leads to glucose intolerance and exacerbates the dysfunction of Irs2-deficient $\beta$ cells (Supplemental Figure 4 and ref. 53). Moreover, transgenic Pdx1 expression can overcome IRS2 deficiency and maintain sufficient $\beta$ cell function to normalize glucose tolerance of Irs $2^{-1-}$ mice $(29,30)$. FOXO1 and Pdx1 display a mutually exclusive pattern of nuclear localization in murine $\beta$ cells (29). Thus, $\beta$ cell survival and function might be mediated, at least in part, by the IRS 2 fFOXO1 cascade. Consistent with this hypothesis, trimeprazine increases nuclear localization of $\mathrm{Pdx} 1$ in $\beta$ cells of control islets, but fails to do so in Irs $2^{-/}$islets. Since trimeprazine reduces the concentration of Pdx1 mRNA in human islets, we investigated the effect of trimeprazine on glucose tolerance and $\beta$ cell function in $P d x 1^{+/-}$mice. As expected, $P d x 1^{+/-}$mice developed glucose intolerance; however, trimeprazine restored normal glucose tolerance and $\beta$ cell function (HOMA2\%B) in $P d x 1^{+/-}$mice. Trimeprazine might promote $\beta$ cell survival and function, at least in part, by promoting nuclear Pdx1 localization, especially under conditions of reduced Pdx1 levels. Unfortunately we failed to detect sufficient $P d x 1$ immunostaining in the $P d x 1^{+/-}$mice to confirm whether increased nuclear Pdx1 might overcome its reduced expression.

To further explore the ability of trimeprazine to protect $\beta$ cells, we investigated its effects in NOD mice, a well-known model of autoimmune T cell-mediated T1DM (54). T1DM is a common, severe, chronic autoimmune disease characterized by the progressive loss of self-tolerance to $\beta$ cells that leads to the destruction of these cells and to hyperglycemia (55). Treatments based on anti-CD3 Abs are an extensively studied immunological approach to the treatment of T1DM and are being used in ongoing clinical trials (56). Brief anti-CD3 treatment (6-14 days) early in the course of T1DM has the potential to alter disease progression, at least in certain patients (56-58). This protective effect depends on residual $\beta$ cell function at or above the 50th percentile at diagnosis (59). Treatment of NOD mice after the onset of diabetes with trimeprazine alone had no effect on the progression of hyperglycemia (data not shown). By comparison, the typical 5-day treatment of hyperglycemic NOD mice with anti-CD3 alone restored normal glycemia for a few days until severe hyperglycemia recurred in the large majority of these mice over the following 2 weeks. By contrast, coadministration of anti-CD3 and trimeprazine for 5 days, together with daily trimeprazine administration for the duration of the experiment, restored the majority of mice to near-normal glycemic levels until the experiment was terminated 22 days later. This treatment was accompanied by more mitogenesis and $\beta$ cell mass, which was absent with anti-CD3 treatment alone. We did not measure the effect of trimeprazine on Irs2 levels in the NOD islets, because the isolation was difficult and the yield was insufficient for protein analysis. Regardless, coadministration of anti-CD3 with drugs that increase Irs2 levels might augment the efficacy of the anti-CD3-induced "tolerant" environment in $\beta$ cell function.

Although our work focuses on the role of tricyclic compounds to increase IRS 2 in $\beta$ cells, these compounds might have other effects that influence glucose tolerance or $\beta$ cell function (60). In neurons, trimeprazine and several analogs can replace or enhance the function of survival of motor neuron 1 (SMN1), which is important for the maintenance of motor neurons (60). Indeed, tricyclic antidepressants such as amitriptyline and nortriptyline are recommended off label as first-line therapy for diabetic peripheral neuropathic pain (61). Tricyclic analogs also promote bone growth by inhibiting the function of SOST (sclerostin), a BMP antagonist that inhibits the Wnt pathway needed for bone formation (62). Trimeprazine, methotrimeprazine, ethopromaizine, and 2 other compounds that increase Irs 2 but fall outside our statistical cutoff (promethazine, 4.3-fold and trimipramine, 3.5-fold) can maintain high expression levels of pluripotency markers in human embryonic stem cells (hESCs), which are associated with long-term self-re- 
newal in the absence of basic FGF (bFGF) (63). The mechanism of this effect is unknown, but bFGF signaling, which appears to be emulated by tricyclic compounds, ordinarily promotes various downstream signaling pathways, including MAPK, PI3K $\rightarrow$ AKT, and PLC/PKC (64). Interestingly, PIK3 $\rightarrow$ AKT signaling can promote undifferentiated proliferation by suppressing MAP and Wnt signaling and inhibiting GSK3 $\beta(65,66)$. Therefore, trimeprazine might activate other PI3K-dependent pathways that can promote $\beta$ cell function.

In summary, trimeprazine and its analogs can promote IRS2 expression in human and mouse islets and $\beta$ cells and promote the function of mouse $\beta$ cells in a manner that is sufficient to improve glucose tolerance in various models of diabetes. Trimeprazine and its analogs increase IRS2 in human islets, which is consistent with its effect in promoting the function of human $\beta$ cells transplanted into mice. Even if these compounds fail to promote the growth of human $\beta$ cells, it is likely that more IRS2 can improve the function and stability of the graft after transplantation, especially during metabolic or immunologic stress (39). Identification of the cohort of GPCRs that are engaged by trimeprazine on islets might reveal new targets that can be exploited directly for the treatment of $\beta$ cell dysfunction. Whether other compounds identified by our screen can be used to promote human islet and $\beta$ cell function needs to be examined.

\section{Methods}

Chemical compounds. Chemical libraries for screening were provided by the ICCB-Longwood Screening Facility (http://iccb.med.harvard.edu/) at Harvard Medical School. Four chemical libraries were used, including Biomol ICCB Known Bioactives 1 (480 compounds at approximately $3 \mathrm{mM}$ in DMSO); Biomol ICCB Known Bioactives 2 (480 compounds at $\sim 0.5 \mathrm{mg} / \mathrm{ml}$ in DMSO); Ninds Custom Collection 2 (1,040 compounds at $10 \mathrm{mM}$ in DMSO); and Prestwick 1 Collection (1,120 compounds at $2 \mathrm{mg} / \mathrm{ml}$ in DMSO). These combined libraries cover approximately $47 \%$ of the FDA-approved drugs (these libraries are available via http://iccb.med.harvard.edu/libraries/compound-libraries/). In addition, forskolin (SigmaAldrich); YC-1 (Cayman Chemical); trimeprazine (MicroSource Discovery Systems); and K252A and zardaverdine (Enzo Life Sciences) were purchased for additional analyses.

In vitro screening. We developed a screening assay in a 96-well format based on the Panomics QuantiGene 2.0 Single Plex Assay (Affymetrix) to quantify IRS2 mRNA concentration in isolated human islets. Islets from 12 nondiabetic human cadaveric donors arrived over a period of 1 year in a controlled-temperature package maintained at $15^{\circ} \mathrm{C}$ to $20^{\circ} \mathrm{C}$. The islets were transferred into fresh Miami $1 \mathrm{~A}$ medium (Cellgro) at a density of $500 \mathrm{IEQ} / \mathrm{ml}$ supplemented with $0.01 \mathrm{~g} / 1$ reduced L-glutathione (Sigma-Aldrich) and incubated at $37^{\circ} \mathrm{C}$ and $5 \% \mathrm{CO}_{2}$ for 1 to 2 days to facilitate recovery from transportation prior to the experiments. All fluid manipulations with 96-well plates were performed mechanically at the ICCB-Longwood Screening Facility. The night before the chemical screening, the islets were distributed into 96-well plates at 75 IEQ per well in 99- $\mu 1$ low-glucose phenol red-free DMEM (Gibco) and incubated overnight at $37^{\circ} \mathrm{C}$ and $5 \% \mathrm{CO}_{2}$. The next morning, DMSO $(1 \mu \mathrm{l})$ was added into 5 wells as a basal control; $1 \mu 1$ of 100 $\mathrm{mM} \mathrm{Bt} \mathrm{c}_{2} \mathrm{AMP}$ (Sigma-Aldrich) (final concentration of $1 \mathrm{mM}$ ) was added to 4 wells, and $1 \mu 1$ of $250 \mathrm{nM}$ exendin-4 (Sigma-Aldrich) (final concentration of $2.5 \mathrm{nM}$ ) was added to 4 wells, and the remaining wells were loaded with compounds from the chemical libraries. The plates were incubated for 4 hours at $37^{\circ} \mathrm{C}$ and $5 \% \mathrm{CO}_{2}$. A single assay for each compound was conducted on 2 different occasions using different islet preparations. After incubation, the islets were lysed with buffer provided in the QuantiGene 2.0 kit and processed according to the manufacturer's instructions using a probe system generated at Panomics to target human IRS2 mRNA. The average baseline for each 96-well plate was calculated using the signal from wells containing DMSO alone. After subtraction of the average baseline for each plate, each 96-well plate median was calculated and used to normalize the specific signals for each test well on the plate. The normalized signals for each plate were combined and analyzed by generalized linear regression (SPSS, version 21.0) to identify compounds that increased IRS2 mRNA above the 95th percentile ( $>2.4$-fold, $P<$ $0.05)$ relative to the DMSO baseline. $\mathrm{Bt}_{2} \mathrm{cAMP}$ and 77 of the 3,300 tested compounds $(2.6 \%)$ met this arbitrary cut-off (Supplemental Table 1). At least 121 compounds reduced the expression of IRS2 below the 5th percentile ( $<-1.8$-fold, $P<0.05$ ), but these compounds were not further investigated (data not shown). A small number of compounds that increased IRS2 mRNA levels were retested in triplicate at 4 different concentrations and with islets from 3 different donors. Only nontoxic compounds identified in the database of the Canadian Centre for Occupational Health and Safety (www.ccohs.ca) were used in mice.

Cellular Functional GPCR Profile. The Cellular Functional GPCR Profile of trimeprazine tartrate was 
performed by Cerep Inc. (http://www.cerep.fr/cerep/Users/index.asp). Relative expression of the selected GPCRs in human islets was estimated from array expression data deposited in the NCBI's Gene Expression Omnibus (GEO) database (GEO GSE50398), compiled by the Beta Cell Gene Atlas Tool (http:// www.t1dbase.org/page/AtlasView/display/temp_folder_id/507810/showdata/source/rank/1).

Multiplex analysis of gene expression in human islets. Expression levels of 12 human genes (FOXA2, FOXO1, FOXO3, GLK, GLUT2, INSR, IGF1R, IRS1, IRS2, MAFA, PC1/3, PDX1, GAPDH, PORIN, and PPIB) were determined using a QuantiGene 2.0 Custom Plex Set. The human islets were incubated overnight as described above for in vitro screening, except that each well of a 96-well plate contained 250 IEQ in $130 \mu \mathrm{l}$ Miami $1 \mathrm{~A}$ medium. The next day, the islets were incubated for 5 hours with $1.3 \mu 1$ DMSO alone or with DMSO containing $1 \mathrm{mM} \mathrm{Bt}_{2} \mathrm{CAMP}$ or $20 \mu \mathrm{g} / \mathrm{ml}$ trimeprazine tartrate and analyzed according to the manufacturer's instructions. Conditions were tested in triplicate.

Immunoblot analysis. Human islets were prepared for experiments as described above, and mouse islets were isolated by collagenase digestion of whole mouse pancreas as previously described (27). Islets were transferred into fresh Miami 1A medium and treated with compounds at the concentration indicated in the figure legends for 24 hours at $37^{\circ} \mathrm{C}$ and $5 \% \mathrm{CO}_{2}$. After the treatments, the islets were separated from the medium by centrifugation and frozen immediately in liquid nitrogen and maintained at $-80^{\circ} \mathrm{C}$ until immunoblotting. Islet protein lysates were resolved by SDS-PAGE, transferred to nitrocellulose membranes (Bio$\mathrm{Rad}$ ), and blotted with primary Abs against Irs2 (EMD Millipore; no. MABS15); Irs1 mAb (produced in our laboratory); Pdx1 (Cell Signaling Technology; no. 5679S); FOXO1 (Cell Signaling Technology; no. 2880); FOXO3A (Cell Signaling Technology; no. 2497); CREB (Cell Signaling Technology, no. 9104); phosphorylated CREB (Cell Signaling Technology; no. 8212S); Glut2 (EMD Millipore; no. 07-1402); and tubulin (Cell Signaling Technology; no. 3873S). The density of bands was acquired and analyzed using a Kodak Imaging System and CareStream (version 5.0.7.23). Expression levels were normalized to tubulin as an internal standard.

Mice. Mice were fed ad libitum and kept under a 12-hour light/12-hour dark cycle. IRS2 whole-body$\mathrm{KO}$ male mice (Irs2 ${ }^{--}$) on a C57BL/6 background and their male WT littermates were generated at Boston Children's Hospital and fed Breeder's Diet (5058 PicoLab Mouse Diet 20, with 9\% fat). WT and Irs2-1mice were genotyped by PCR as previously described (23). Female NOD mice were purchased from The Jackson Laboratory and fed a standard chow diet (LabDiet 5P04 Prolab RMH 3500, autoclavable, with 5\% fat). A pair of male and female $P d x 1^{+/-}$mice ( $P d x 1^{\text {tm IMacd }} / \mathrm{J}$; stock no. 005701) for breeding (67) and 25 male beige SCID Fox Chase mice were obtained from The Jackson Laboratory on a C57BL/b background and maintained at the Joslin Diabetes Center on an ad libitum lab diet (PicoLab Chow; no. 5058, with 9\% fat). For all the experiments, blood samples were collected by tail bleeding between 8 am and 9 am, and circulating glucose levels were determined using a glucometer (Bayer Elite). Serum mouse insulin levels were measured in tail blood using an insulin ELISA kit (Crystal Chemical); human insulin or human c-peptide in the beige SCID Fox Chase mice transplanted with human islets was measured with specific ELISA kits from ALPCO. Intraperitoneal glucose tolerance tests (IPGTTs) were performed in overnight fasted (15-16 hours) mice after i.p. injection of $2 \mathrm{~g}$ D-glucose per kilogram of body weight (68).

Drug treatments. WT, Irs $2^{-/}$, and $P d x 1^{+/-}$mice received compound treatments beginning between 5 and 6 weeks of age. The compounds were dissolved in DMSO or saline (depending on solubility), with injections of corresponding vehicle used as a negative control. Litter-matched WT, Irs $2^{-/}$, or $P d x 1^{+/-}$mice were randomly divided into control (vehicle-treated) or experimental (compound-treated) groups. Each mouse received a single i.p. injection of trimeprazine $(10 \mathrm{mg} / \mathrm{kg}$ ) on weekdays (omitting Saturdays and Sundays) for 3 weeks. The trimeprazine dose was increased gradually over 3 days $(2.5 \mathrm{mg} / \mathrm{kg}, 5 \mathrm{mg} / \mathrm{kg}$, and $10 \mathrm{mg} /$ $\mathrm{kg}$ ) to avoid its initial sedative effects. The days of injections for the experiment were counted from the full dose of $10 \mathrm{mg} / \mathrm{kg}$.

For NOD mice, hyperglycemia was confirmed by random fed [glucose] $>200 \mathrm{mg} / \mathrm{dl}$ measured twice over a 2- to 3-hour test interval. Diabetic NOD mice received i.p. injections of ( $10 \mu \mathrm{g} / \mathrm{mouse})$ of anti-CD3 $\mathrm{Ab}$ (mAb 145-2C11, see ref. 69) over 5 consecutive days, with or without $10 \mathrm{mg} / \mathrm{kg}$ trimeprazine. The female NOD mice used in this experiment never displayed sedation as a result of trimeprazine administration, so a full dose was used immediately upon the onset of diabetes. Treatment with or without trimeprazine was continued for the next 17 days, while random blood glucose levels were measured at the time intervals indicated in the legend to Figure 7.

Histological analysis. Mice were injected with or without the thymidine analog BrdU (100 mg/kg), as 
indicated in legends to Figures 6 and 7. For Irs $2^{-1-}$ and WT mice, the BrdU injection was performed twice at $4 \mathrm{pm}$ on 2 consecutive days, and mice were sacrificed at 10 am the morning after the second injection. NOD mice treated with or without trimeprazine for 21 days were injected with BrdU at $4 \mathrm{pm}$ and sacrificed the next morning at 10 am (day 22 after the onset of diabetes). Dissected pancreata were fixed with $4 \%$ paraformaldehyde overnight at $4^{\circ} \mathrm{C}$ and then transferred to $30 \%$ sucrose for overnight incubation at $4^{\circ} \mathrm{C}$. Next, the tissues were embedded in O.C.T. Compound (Tissue-Tek), frozen and cut into $10-\mu \mathrm{m}$ sections for mounting. For each mouse, at least 2 total pancreas sections, separated from each other by at least $200 \mu \mathrm{m}$, were analyzed. Pancreas sections were permeabilized using $0.2 \%$ Triton X-100/PBS, and antigen unmasking was performed in a boiling solution of $0.01 \mathrm{M}$ sodium citrate ( $\mathrm{pH}$ 6.0) for 20 minutes. Sections were blocked with normal goat serum for 1 hour and incubated overnight $\left(4^{\circ} \mathrm{C}\right)$ with guinea pig anti-insulin (1:100; Invitrogen; no. 18-0067) and rat anti-BrdU (1:250; Abcam; no. ab6326). Next, the sections were incubated for 1 hour at $22^{\circ} \mathrm{C}$ with DAPI nuclear stain (Invitrogen, at a final concentration of $0.3 \mu \mathrm{M}$ ) in ProLong Diamond Antifade Mountant (Thermo Fisher Scientific; no. P36961), together with one of the following secondary Abs (1:200 dilution) obtained from Cell Signaling Technology: no. 4412, anti-rabbit IgG (H+L), F(ab')2 Fragment (Alexa Fluor 488); no. 8889, anti-rabbit IgG (H+L), F(ab')2 Fragment (Alexa Fluor 594); no. 4414, anti-rabbit IgG (H+L), F(ab')2 Fragment (Alexa Fluor 647); or no. 7076, anti-mouse IgG, HRP-linked Ab. Composite images were created from a $10 \times 10$ array of adjacent nonoverlapping $\times 10$ magnification images with an Axiovert Zeiss LSM 510 microscope. Images were examined for insulinpositive staining using the Zeiss LSM Image Browser, version 4.2.0.121, and the intensity of immunostaining was determined using Spot (Spot Imaging Solutions) or IMARIS Bitplane, version 7.6.5.

$P d x 1$ nuclear localization and summarization by $P d x 1^{>M E D}$. Pancreas sections from mice in each treatment group were immunostained with Abs against insulin and Pdx1 (Cell Signaling Technology; no. 5679S, D59H3 XP Rabbit mAb) and stained with DAPI to distinguish the nuclei from the cytosol. The immunostaining was separated into components and quantified by IMARIS Bitplane software, version 7.6.5. The average cytoplasmic Pdx1 immunostaining of each islet $\left(\mathrm{Cyto}^{\mathrm{Pdx} 1}\right)$ was used to normalize the nuclear Pdx1 immunostaining ( $\mathrm{Nuc}^{\mathrm{Pdx} 1}$ ) of each nucleus in each islet. The median-of-ratios in control islets (Nuc ${ }^{\mathrm{Pdx} 1} /$ Cyto $^{\text {Pdx1 }}$ ) was $0.95(n=926$ nuclei, $95 \% \mathrm{CI}=0.93-0.98)$. The number of nuclei above the $95 \%$ CI was determined in each islet (\#Nuc ${ }^{\mathrm{Pdx} 1}$ ) and divided by the total number of nuclei in the islet (\#Nuc ${ }^{\mathrm{Tot}}$ ) to obtain a relative estimate of nuclei with $\mathrm{Pdx} 1$ immunostaining above the median $\left(\mathrm{Pdx} 1^{>\mathrm{MED}}\right.$ ) (see Supplemental Table 2). The values for $\operatorname{Pdx} 1^{>M E D}$ obtained for each experimental group were compared by a GLM, with genotype and drug treatment as interacting factors and a Bonferroni correction for multiple comparisons.

Human islet transplantation into diabetic mice. Diabetes in male beige SCID Fox Chase mice (The Jackson Laboratory) was induced by a single i.p. injection of $140 \mathrm{mg} / \mathrm{dl}$ STZ (Sigma-Aldrich). Fed blood glucose levels above $300 \mathrm{mg} / \mathrm{dl}$ were considered diabetic and suitable for transplantation. Sixteen diabetic mice were anesthetized using ketamine/xylazine and placed on a heated plate for surgery. The left kidney was exposed through a lumbar incision, and the kidney capsule was incised. Using a Hamilton syringe (Fisher Scientific) and PE50 polyethylene tubing, 800 human islet equivalents (IE) were placed under the kidney capsule as previously described (70). The mice were randomized into 2 groups of 8 mice each. One group received daily saline injections $(10 \mathrm{ml} / \mathrm{kg})$ beginning 3 days after islet transplantation. The other group received an initial dose of $2.5 \mathrm{mg} / \mathrm{kg}$ trimeprazine, followed by $5 \mathrm{mg} / \mathrm{kg}$ the next day, and $10 \mathrm{mg} / \mathrm{kg}$ daily injections until the experiments were terminated. Blood glucose concentrations were measured in the tail blood with a OneTouch Ultra2 blood glucose meter (Life Scan Inc.) once per week at 8 am. Seventy-four days after the experiment was initiated, mouse insulin, human insulin, and human c-peptide levels were measured in fed mice. The next day, an IPGTT was conducted, the mice were anesthetized, and the kidneys containing the human grafts were excised and fixed in $4 \%$ paraformaldehyde for 2 hours and stored in PBS at $4^{\circ} \mathrm{C}$ until paraffin embedding. Serial sections $(5-\mu \mathrm{m})$ of the entire graft were obtained. Selected sections were stained for insulin, (guinea pig anti-human insulin; Dako North America; 1:100 overnight). Sections were photographed using a Leica M420 microscope with a Nikon camera and NIS Elements software. The area of each selected section was determined using ImageJ, version $1.49 \mathrm{p}(\mathrm{NIH})$ and plotted against the position of the section. The volume of the insulin stained area was estimated by calculating the AUC using Medcalc, version 15.10.0.

Statistics. The average \pm SEM or median values, as indicated in the figure legends, were calculated using SPSS, version 19 or version 23, or Analyze-it, version 4.43 or version 5.51. Correlation coefficients were calculated with Analyze-it. Median values are shown with a black horizontal line surrounded by a box from 
the first to third quartiles, and whiskers with end caps extending from the minimum to maximum values. A GLM using SPSS, version 19 or 23, was used to compare results where indicated. Bonferroni's test was used to correct the $P$ values for multiple comparisons where necessary. A $P$ value of less than 0.05 was considered statistically significant. Where indicated, statistical outliers were determined by ROUT (Q = 10\%) (71).

Study approval. All animal studies were approved by the IACUC of Boston Children's Hospital and the Joslin Diabetes Center. Human donor islets were obtained from the Islet Cell Resource Center (Integrated Islet Distribution Program [IDP], https://iidp.coh.org/) and declared exempt from approval by the IRB of Boston Children's Hospital.

\section{Author contributions}

AK conducted the screen and performed the experiments depicted in Figures 1-8. YY performed the measurements and analysis for Figure 8, and JHL performed the human islet transplantation experiment depicted in Figure 8. LOA developed the chemical screen using human islets. AR conducted the immunofluorescence experiments. MS performed immunoblot analysis for Figure 4. LN developed the strategy for the NOD mouse experiment. JR interpreted the tricyclic compound results. IEK and AS assisted with the $P d x 1^{+/-}$mouse experiments. SBW and GCW shared key insights and strategies for the human islet transplantation experiments. MFW analyzed and assembled the data and wrote the manuscript.

\section{Acknowledgments}

This work was supported by grants from the Iacocca Foundation (76776-01); the Juvenile Diabetes Foundation International (1-2005-839 and 17-2012-427); and the NIH (DK38712 and DK98655, to M.F. White).

Address correspondence to: Morris F. White, Division of Endocrinology, Boston Children's Hospital, Harvard Medical School, CLS, Rm 16020, 3 Blackfan Circle, Boston, Massachusetts 02115, USA. Phone: 617.919.2846; E-mail: morris.white@childrens.harvard.edu.

Alexandra Kuznetsova's present address is: Felicitex Therapeutics, Watertown, Massachusetts, USA.

Marianna Sadagurski's present address is: University of Michigan, Ann Arbor, Michigan, USA.

Lisa Norquay’s present address is: Janssen Pharmaceuticals, Inc., Titusville, New Jersey, USA.

Arun Sharma's present address is: MedImmune, LLC, Gaithersburg, Maryland, USA.

1. Chen L, Magliano DJ, Zimmet PZ. The worldwide epidemiology of type 2 diabetes mellitus — present and future perspectives. Nat Rev Endocrinol. 2012;8(4):228-236.

2. Atkinson MA, Rhodes CJ. Pancreatic regeneration in type 1 diabetes: dreams on a deserted islet? Diabetologia. 2005;48(11):2200-2202.

3. Atkinson MA, et al. How does type 1 diabetes develop?: the notion of homicide or beta-cell suicide revisited. Diabetes. 2011;60(5):1370-1379.

4. Morris AP, et al. Large-scale association analysis provides insights into the genetic architecture and pathophysiology of type 2 diabetes. Nat Genet. 2012;44(9):981-990.

5. Gutierrez JS, et al. Disruption of IRS-2 causes type 2 diabetes in mice. Diabetes. 1998;47(6670):900-904.

6. Hennige AM, et al. Upregulation of insulin receptor substrate- 2 in pancreatic $\beta$ cells prevents diabetes. J Clin Invest. 2003;112(10):1521-1532.

7. Hennige AM, et al. Alterations in growth and apoptosis of insulin receptor substrate-1-deficient $\beta$-cells. Am J Physiol Endocrinol Metab. 2005;289(2):E337-EE46.

8. Norquay LD, et al. Insulin receptor substrate-2 in $\beta$-cells decreases diabetes in nonobese diabetic mice. Endocrinology. 2009;150(10):4531-4540.

9. White MF. Regulating insulin signaling and $\beta$-cell function through IRS proteins. Can J Physiol Pharmacol. 2006;84(7):725-737.

10. Assmann A, Ueki K, Winnay JN, Kadowaki T, Kulkarni RN. Glucose effects on $\beta$-cell growth and survival require activation of insulin receptors and insulin receptor substrate 2. Mol Cell Biol. 2009;29(11):3219-3228.

11. Ahren B. Islet G protein-coupled receptors as potential targets for treatment of type 2 diabetes. Nat Rev Drug Discov. 2009;8(5):369-385.

12. Jhala US, et al. cAMP promotes pancreatic $\beta$-cell survival via CREB-mediated induction of IRS2. Genes Dev. 2003;17(13):1575-1580.

13. Demozay D, Tsunekawa S, Briaud I, Shah R, Rhodes CJ. Specific glucose-induced control of insulin receptor substrate-2 expression is mediated via $\mathrm{Ca}^{2+}$-dependent calcineurin/NFAT signaling in primary pancreatic islet $\beta$-cells. Diabetes. 2011;60(11):2892-2902. 
14. Tsunekawa S, et al. FoxO feedback control of basal IRS-2 expression in pancreatic $\beta$-cells is distinct from that in hepatocytes. Diabetes. 2011;60(11):2883-2891.

15. Winzell MS, Ahren B. G-protein-coupled receptors and islet function-implications for treatment of type 2 diabetes. Pharmacol Ther. 2007;116(3):437-448.

16. Frantz S. Drug discovery: playing dirty. Nature. 2005;437(7061):942-943.

17. Jain S, Ruiz de Azua I, Lu H, White MF, Guettier JM, Wess J. Chronic activation of a designer G(q)-coupled receptor improves $\beta$ cell function. J Clin Invest. 2013;123(4):1750-1762.

18. Zhao Z, et al. Repurposing cAMP-modulating medications to promote $\beta$-cell replication. Mol Endocrinol. 2014;28(10):1682-1697.

19. Antihistamines, Phenothiazine-derivative (Systemic). Drugs.com Web site. www.drugs.com/mmx/trimeprazine-tartrate.html. Accessed February 23, 2016.

20. Soleimanpour SA, et al. Calcineurin signaling regulates human islet \{beta\}-cell survival. J Biol Chem. 2010;285(51):40050-40059.

21. Withers DJ, et al. Disruption of IRS-2 causes type 2 diabetes in mice. Nature. 1998;391(6670):900-904.

22. Hennige AM, Burks DJ, Schubert M. Overexpression of IRS2 in $\beta$-cells is sufficient to suppress diabetes in IRS2 ${ }^{-/-}$mice and insulin resistant C57/B16 mice. Diabetes. 2002;51(2):A377.

23. Park S, et al. Exendin-4 uses Irs2 signaling to mediate pancreatic beta cell growth and function. J Biol Chem. 2006;281(2):1159-1168.

24. Antao B, Ooi K, Ade-Ajayi N, Stevens B, Spitz L. Effectiveness of alimemazine in controlling retching after Nissen fundoplication. J Pediatr Surg. 2005;40(11):1737-1740.

25. Simonoff EA, Stores G. Controlled trial of trimeprazine tartrate for night waking. Arch Dis Child. 1987;62(3):253-257.

26. Herman SM, Vender RB. Antihistamines in the treatment of dermatitis. J Cutan Med Surg. 2003;7(6):467-473.

27. Cerep SA. Company Web site. http://www.cerep.fr/Cerep/Users/index.asp. Accessed March 3, 2016.

28. Sachdeva MM, Stoffers DA. Minireview: Meeting the demand for insulin: molecular mechanisms of adaptive postnatal beta cel mass expansion. Mol Endocrinol. 2009;23(6):747-758.

29. Kitamura T, et al. The forkhead transcription factor Foxo1 links insulin signaling to Pdx1 regulation of pancreatic $\beta$ cell growth J Clin Invest. 2002;110(12):1839-1847.

30. Kushner JA, et al. Pdx1 restores beta cell function in Irs2 knockout mice. J Clin Invest. 2002;109(9):1193-1201.

31. Humphrey RK, Yu SM, Flores LE, Jhala US. Glucose regulates steady-state levels of PDX1 via the reciprocal actions of GSK3 and AKT kinases. J Biol Chem. 2010;285(5):3406-3416.

32. Liu Y, et al. Conditional ablation of Gsk-3 $\beta$ in islet beta cells results in expanded mass and resistance to fat feeding-induced diabetes in mice. Diabetologia. 2010;53(12):2600-2610.

33. Anderson MS, Bluestone JA. The NOD mouse: a model of immune dysregulation. Annu Rev Immunol. 2005;23:447-485.

34. Sherry NA, et al. Exendin-4 improves reversal of diabetes in NOD mice treated with anti-CD3 monoclonal antibody by enhancing recovery of $\beta$-cells. Endocrinology. 2007;148(11):5136-5144.

35. Ablamunits V, et al. Synergistic reversal of type 1 diabetes in NOD mice with anti-CD3 and interleukin-1 blockade: evidence of improved immune regulation. Diabetes. 2012;61(1):145-154.

36. Dean Y, Depis F, Kosco-Vilbois M. Combination therapies in the context of anti-CD3 antibodies for the treatment of autoimmune diseases. Swiss Med Wkly. 2012;142:w13711.

37. Levitt HE, et al. Glucose stimulates human $\beta$ cell replication in vivo in islets transplanted into NOD-severe combined immunodeficiency (SCID) mice. Diabetologia. 2011;54(3):572-582.

38. Rao P, Cozar-Castellano I, Roccisana J, Vasavada RC, Garcia-Ocana A. Hepatocyte growth factor gene therapy for islet transplantation. Expert Opin Biol Ther. 2004;4(4):507-518.

39. Rhodes CJ, White MF, Leahy JL, Kahn SE. Direct autocrine action of insulin on $\beta$-cells: does it make physiological sense? Diabetes. 2013;62(7):2157-2163.

40. Tanabe K, et al. Genetic deficiency of glycogen synthase kinase-3 $\beta$ corrects diabetes in mouse models of insulin resistance. PLoS Biol. 2008;6(2):e37.

41. Elghazi L, Bernal-Mizrachi E. Akt and PTEN: $\beta$-cell mass and pancreas plasticity. Trends Endocrinol Metab. 2009;20(5):243-251.

42. Kulkarni RN, Mizrachi EB, Ocana AG, Stewart AF. Human $\beta$-cell proliferation and intracellular signaling: driving in the dark without a road map. Diabetes. 2012;61(9):2205-2213.

43. Bernal-Mizrachi E, Kulkarni RN, Scott DK, Mauvais-Jarvis F, Stewart AF, Garcia-Ocana A. Human $\beta$-cell proliferation and intracellular signaling part 2: still driving in the dark without a road map. Diabetes. 2014;63(3):819-831.

44. Costes S, Langen R, Gurlo T, Matveyenko AV, Butler PC. $\beta$-Cell failure in type 2 diabetes: a case of asking too much of too few? Diabetes. 2013;62(2):327-335.

45. Lingohr MK, et al. Specific regulation of IRS-2 expression by glucose in rat primary pancreatic islet beta-cells. $J$ Biol Chem 2006;281(23):15884-15892.

46. Awazawa M, et al. Adiponectin enhances insulin sensitivity by increasing hepatic IRS-2 expression via a macrophage-derived IL-6-dependent pathway. Cell Metab. 2011;13(4):401-412.

47. Scott LJ. Repaglinide: a review of its use in type 2 diabetes mellitus. Drugs. 2012;72(2):249-272

48. Li D, et al. The repression of IRS2 gene by ATF3, a stress-inducible gene, contributes to pancreatic $\beta$-cell apoptosis. Diabetes. 2008;57(3):635-644

49. Briaud I, Dickson LM, Lingohr MK, McCuaig JF, Lawrence JC, Rhodes CJ. Insulin receptor substrate-2 proteasomal degradation mediated by a mammalian target of rapamycin (mTOR)-induced negative feedback down-regulates protein kinase B-mediated signaling pathway in $\beta$-cells. J Biol Chem. 2005;280(3):2282-2293.

50. Weston-Green K, Huang XF, Deng C. Second generation antipsychotic-induced type 2 diabetes: a role for the muscarinic M3 receptor. CNS Drugs. 2013;27(12):1069-1080.

51. Genois A, Haig M, Des Roches A, Sirard A, Le May S, McCuaig CC. Case report of atopic dermatitis with refractory pruritus markedly improved with the novel use of clonidine and trimeprazine. Pediatr Dermatol. 2014;31(1):76-79.

52. Yuan Y, et al. A small-molecule inducer of PDX1 expression identified by high-throughput screening. Chem Biol. 2013;20(12):1513-1522

53. Kulkarni RN, Jhala US, Winnay JN, Krajewski S, Montminy M, Kahn CR. PDX-1 haploinsufficiency limits the compensatory 
islet hyperplasia that occurs in response to insulin resistance. J Clin Invest. 2004;114(6):828-836.

54. Leiter EH, Schile A. Genetic and pharmacologic models for type 1 diabetes. Curr Protoc Mouse Biol. 2013;3(1):9-19.

55. Waldron-Lynch F, Herold KC. Immunomodulatory therapy to preserve pancreatic $\beta$-cell function in type 1 diabetes. Nat Rev Drug Discov. 2011;10(6):439-452.

56. Skyler JS. The compelling case for anti-CD3 in type 1 diabetes. Diabetes. 2013;62(11):3656-3657.

57. Keymeulen B, et al. Four-year metabolic outcome of a randomised controlled CD3-antibody trial in recent-onset type 1 diabetic patients depends on their age and baseline residual $\beta$ cell mass. Diabetologia. 2010;53(4):614-623.

58. Chatenoud L, Bluestone JA. CD3-specific antibodies: a portal to the treatment of autoimmunity. Nat Rev Immunol. 2007;7(8):622-632.

59. Keymeulen B, et al. Insulin needs after CD3-antibody therapy in new-onset type 1 diabetes. N Engl J Med. 2005;352(25):2598-2608

60. Dreyfuss G, Wang J, inventors; The Trustees Of The University Of Pennsylvania, assignee. Method of treating neurological diseases disorders. US Patent US8188070 B2. May 29, 2012.

61. Lindsay TJ, Rodgers BC, Savath V, Hettinger K. Treating diabetic peripheral neuropathic pain. Am Fam Physician. 2010;82(2):151-158

62. Ellies D, Rosenberg W. Trimeprazine and ethopropazine derivatives for promoting bone growth. US Patent No. US 2010/0055183 A1. Google Patents; 2010. https://www.google.com/patents/US20100055183

63. Kumagai H, Suemori H, Uesugi M, Nakatsuji N, Kawase E. Identification of small molecules that promote human embryonic stem cell self-renewal. Biochem Biophys Res Commun. 2013;434(4):710-716.

64. Dorey K, Amaya E. FGF signalling: diverse roles during early vertebrate embryogenesis. Development. 2010;137(22):3731-3742.

65. Singh AM, et al. Signaling network crosstalk in human pluripotent cells: a Smad2/3-regulated switch that controls the balance between self-renewal and differentiation. Cell Stem Cell. 2012;10(3):312-326.

66. Bechard M, Trost R, Singh AM, Dalton S. Frat is a phosphatidylinositol 3-kinase/Akt-regulated determinant of glycogen synthase kinase 3beta subcellular localization in pluripotent cells. Mol Cell Biol. 2012;32(2):288-296.

67. Holland AM, Hale MA, Kagami H, Hammer RE, MacDonald RJ. Experimental control of pancreatic development and maintenance. Proc Natl Acad Sci U S A. 2002;99(19):12236-12241.

68. Copps KD, Hancer NJ, Opare-Ado L, Qiu W, Walsh C, White MF. Irs1 serine 307 promotes insulin sensitivity in mice. Cell Metab. 2010;11(1):84-92.

69. Herold KC, et al. Prevention of autoimmune diabetes with nonactivating anti-CD3 monoclonal antibody. Diabetes. 1992;41(3):385-391.

70. Davalli AM, et al. Function, mass, and replication of porcine and rat islets transplanted into diabetic nude mice. Diabetes. 1995;44(1):104-111.

71. Motulsky HJ, Brown RE. Detecting outliers when fitting data with nonlinear regression - a new method based on robust nonlinear regression and the false discovery rate. BMC Bioinformatics. 2006;7:123. 